\title{
Influence of tropical cyclones on sea surface temperature seasonal cycle and ocean heat transport
}

\author{
Emmanuel M. Vincent • Gurvan Madec • \\ Matthieu Lengaigne · Jérôme Vialard • \\ Ariane Koch-Larrouy
}

Received: 5 July 2012/ Accepted: 1 October 2012

(c) Springer-Verlag Berlin Heidelberg 2012

\begin{abstract}
Recent studies suggested that tropical cyclones (TCs) contribute significantly to the meridional oceanic heat transport by injecting heat into the subsurface through mixing. Here, we estimate the long-term oceanic impact of TCs by inserting realistic wind vortices along observed TCs tracks in a $1 / 2^{\circ}$ resolution ocean general circulation model over the 1978-2007 period. Warming of TCs' cold wakes results in a positive heat flux into the ocean (oceanic heat uptake; OHU) of $\sim 480 \mathrm{TW}$, consistent with most recent estimates. However, $\sim 2 / 5$ of this OHU only compensates the heat extraction by the TCs winds during their passage. Another $\sim 2 / 5$ of this $\mathrm{OHU}$ is injected in the seasonal thermocline and hence released back to the atmosphere during the following winter. Because of zonal compensations and equatorward transport, only one-tenth of the OHU is actually exported poleward (46 TW), resulting in a marginal maximum contribution of TCs to the poleward ocean heat transport. Other usually neglected TC-related processes however impact the ocean mean state. The residual Ekman pumping associated with TCs results in a sea-level drop (rise) in the core (northern and southern flanks) of TC-basins that expand westward into the whole basin as a result of planetary wave propagation. More importantly, TC-induced mixing and air-sea fluxes cool the surface in TC-basins during summer, while the re-emergence of subsurface warm anomalies warms it during
\end{abstract}

E. M. Vincent $(\varangle) \cdot$ G. Madec $\cdot$ M. Lengaigne $\cdot$ J. Vialard LOCEAN-IPSL, IRD/CNRS/UPMC/MNHN, tour 45-55 4e,

4, place Jussieu, 75252 Paris Cedex 5, France

e-mail: emmanuel.vincent@locean-ipsl.upmc.fr

G. Madec

NOC, Southampton, UK

A. Koch-Larrouy

LEGOS, IRD/CNRS/UPS, Toulouse, France winter. This leads to a $\sim 10 \%$ reduction of the sea surface temperature seasonal cycle within TCs basins, which may impact the climate system.

Keywords Tropical cyclones - Ocean heat transport . Seasonal cycle $\cdot$ SST

\section{Introduction}

Intense winds associated with tropical cyclones (TCs) cause vigorous upper-ocean vertical mixing. This mixing cools the ocean upper layers, while injecting warm surface waters downward (Emanuel 2001). Because surface fluxes act to restore cold surface anomalies to background conditions, this results in a net warming of the tropical ocean at the end of the TC season. Emanuel (2001) argued that this net ocean heat uptake $(\mathrm{OHU})$ in the tropics has to be equilibrated by a net ocean heat transport (OHT) out of the tropics, implying that TCs may significantly contribute to the poleward ocean heat transport. Using a one-dimensional ocean model, Emanuel (2001) estimated the yearly averaged TC-induced OHU to be $1.4 \pm 0.7 \mathrm{PW}\left(1 \mathrm{PW}=10^{15} \mathrm{~W}\right)$. Sriver et al. (2008) repeated the calculation using a more extensive data set, but a somewhat cruder model, and found a yearly averaged TC-induced OHU of $0.48 \mathrm{PW}$. Jansen et al. (2010) revisited the calculation and end up with a slightly larger estimate $(0.58 \mathrm{PW})$. The order of magnitude of the total heat transported out of the tropics by the ocean being approximately 2.9 PW (Fasullo and Trenberth 2008), the OHU induced by TCs may imply a significant role of TCs on the climate system as suggested by Emanuel (2001) and Sriver et al. (2008).

Modeling studies (Korty et al. 2008; Jansen and Ferrari 2009; Sriver et al. 2010) have then attempted to quantify 
the TCs' impact on the OHT. Results from these studies however reveal a large sensitivity to the numerical design of the experiments, with a TC contribution to local heat transport at $20^{\circ}$ ranging from 0.05 to $0.4 \mathrm{PW}$ depending on the considered study. The aforementioned studies parameterized TC-induced mixing effect by enhancing vertical diffusivity in the tropical regions. This simplified approach is however very sensitive to the latitudinal (Jansen and Ferrari 2009) and longitudinal (Sriver et al. 2010) extents of TC-induced mixing. The oceanic response to these parameterizations also relies on several strong assumptions regarding the depth over which TC-induced mixing is applied (usually set to a few hundred meters), its magnitude, and the period over which this additional mixing is applied (Manucharyan et al. 2011).

The TC-induced OHU may also be overestimated in the observation-based studies (Emanuel 2001; Sriver et al. 2008) because most of them assumed that all the heat injected below the mixed layer during the summer cyclonic season remains in the ocean. The analysis by Jansen et al. (2010) however estimates that only one quarter of the TCinduced $\mathrm{OHU}$ remains in the permanent thermocline after winter. This study suggests that the mixed layer deepening in winter re-entrains most of the warm sub-surface anomalies generated during the cyclonic season, thus preventing the bulk of the warm anomalies from being advected poleward. Accounting for this seasonality, they re-evaluated the influence of TCs on the OHT to $0.15 \mathrm{PW}$ $( \pm 100 \%)$. Jansen and Ferrari (2009) also pointed out that a substantial part of the $\mathrm{OHU}$ is advected equatorward by the wind-driven circulation and hence does not contribute to the poleward export.

The aforementioned studies assumed that the entire TCinduced surface cooling is attributable to vertical mixing. This may also lead to an overestimation of the TC-induced heat injection into the ocean. Indeed, observational (Park et al. 2011; Trenberth and Fasullo 2007) and modeling studies (Vincent et al. 2012a) indicate that a substantial part of the surface cooling may be related to enthalpy fluxes, especially for weak storms and/or a few hundreds of kilometers away from the storm.

Trenberth and Fasullo (2007) further suggested that these fluxes might as well influence the tropical sea surface temperature (SST) climatology. Hart (2011) hypothesized that TC-induced processes during summer season might affect the subsequent winter climate by modifying the meridional heat flux. TC-induced dynamical processes may as well impact the long-term oceanic state: the strong upwelling generated by TC winds near the cyclone track results in a westward radiating negative sea level anomaly (Jansen et al. 2010). Jullien et al. (2012) and Scoccimarro et al. (2011) suggested that the TC-winds strengthen the wind stress curl at the center of TC basins and contribute to background Ekman pumping. The climatic effect of TCs through their impact on surface heat fluxes and ocean dynamical processes hence deserves further investigation.

Previous global numerical studies investigating TCs climatological impacts used ocean models with rather coarse resolution $\left(\sim 2^{\circ}-4^{\circ}\right.$ horizontal resolution), and most of them accounted for TCs influence by enhancing upper-ocean vertical diffusivity. The aim of the present paper is to investigate the climatological ocean response to TCs using a higher resolution model that allows an explicit representation of TC forcing. We analyze a set of $1 / 2^{\circ}$ global ocean model simulations that include TC-wind forcing at the ocean surface over a 30-year period (1978-2007). TC wind forcing is applied along observed TC-tracks using the Willoughby et al. (2006) analytical vortex, with maximum winds amplitude and TC position derived from observations. This strategy captures the TC-induced surface cooling reasonably well (Vincent et al. 2012a) and allows accounting for TCinduced mixing, but also for the potential impacts of TCinduced dynamical response and surface heat fluxes.

The paper is organized as follow. Section 2 summarizes our numerical framework and describes the experiments designed for separating the respective influence of mixing, advective processes and surface heat fluxes on the TCinduced ocean response. Section 3 describes the ocean response associated with each of these processes at the storm scale. Section 4 then discusses the contribution of these processes to the climatological TC-induced oceanic response and quantifies the TCs importance on the oceanic heat budget and transport. Section 5 provides a summary of our conclusions and their implications.

\section{Numerical strategy}

Vincent et al. (2012a) describe the model configuration, the strategy to include TC forcing and two of the experiments analyzed in this study. The following section provides a short summary of this modeling framework and details three additional sensitivity experiments specifically designed for this study that allow separating the respective contribution of mixing, dynamical response and surface heat fluxes in the ocean response to TCs.

\subsection{Ocean model and additional TC-forcing}

We use a $1 / 2^{\circ}$ global ocean model configuration (known as ORCA05; Biastoch et al. 2009) built from the NEMO (Nucleus of European Model of the Ocean, version 3.2; Madec 2008). This version uses a Turbulent Kinetic Energy (TKE) closure scheme Blanke and Delecluse (1993) improved by including the effect of Langmuir cells (Axell 2002), a surface wave breaking parameterization 
(Mellor and Blumberg 2004) and an energetically consistent time and space discretization (Burchard 2002; Marsaleix et al. 2008). This model successfully reproduces tropical ocean variability at intra-seasonal to decadal time scales (Penduff et al. 2010; Lengaigne et al. 2012; Keerthi et al. 2012, Nidheesh et al. 2012).

The experiment starts from an ocean at rest, initialized with temperature and salinity fields from the World Ocean Atlas 2005 (Locarnini et al. 2010). It is then spun up for a 30-year period (1948-1977) using the COREII bulk formulae and interannual forcing dataset (Large and Yeager 2009; Griffies et al. 2009). This final state is then used to start the simulations described hereafter, which cover the 1978-2007 period.

The cyclone-free simulation (FILT) is forced by the interannual COREII forcing. The COREII forcing strongly underestimates the intensity of observed cyclones (Vincent et al. 2012a). We filter out these underestimated TC-like vortices by applying an 11-day running mean to the wind components within $600 \mathrm{~km}$ of each cyclone track position from IBTrACS (with a linear transition zone to unfiltered winds between $600 \mathrm{~km}$ and 1,200 km of the cyclone tracks).

The cyclone simulation (CYCL) is forced by realistic TC winds superimposed to the FILT forcing. The 6-hourly cyclone position and maximum winds of the 3,000 named TCs from the IBTrACS database (Knapp et al. 2010) are temporally interpolated to the model timestep (i.e. every $36 \mathrm{~min}$ ). This information is used to reconstruct the $10 \mathrm{~m}$-wind vector from an idealized analytical TC wind vortex fitted to observations (Willoughby et al. 2006). This model simulation has been shown to successfully reproduce the mean state of two important parameters involved in the amplitude of the SST response to TCs, namely the depth of the mixed layer and the Cooling Inhibition index, a proxy of the upper ocean density stratification, as well as the local SST response to TC winds forcing (Vincent et al. 2012a; Neetu et al. 2012). A more detailed description of this forcing strategy and of the model validation can be found in Vincent et al. (2012a).

In the following, we computed TC-induced ocean mean state changes as the 1983-2007 (25 years) average difference between CYCL and FILT experiments. We exclude the first 5 years of the experiments, which display a transient adjustment of the upper $400 \mathrm{~m}$ to TC forcing: the difference in total heat content between the two simulation has a clear initial adjustment phase over the first 5 years, and then becomes more stable (not shown).

\subsection{Sensitivity of TC surface forcing to horizontal resolution}

The $1 / 2^{\circ}$ horizontal resolution used in the present study is rather coarse compared to previous case studies simulating the ocean response to single TCs (e.g. Halliwell et al. 2011).
Our forcing strategy is however a good compromise between accuracy and numerical cost for a realistic simulation of the climatological global ocean response to TCs. Indeed, a major requirement for a realistic ocean response to TC forcing is to accurately capture the maximum winds of the TC eyewall in the atmospheric forcing (Halliwell et al. 2011). The use of an analytic TC vortex fitted to observed TCs characteristics allows fulfilling such a requirement. It is then crucial that the spatio-temporal sampling of the ocean grid allows capturing accurately the key processes involved in the ocean response to TC wind forcing, such as vertical mixing and upwelling. The ability of the ocean grid to capture the TC-induced mixing can be evaluated by calculating the TC Power Dissipation (PD): $P D=\rho_{a} C_{D}|\mathbf{V}|^{3}$ where $C_{D}$ is the surface drag coefficient, $\rho_{a}$ the surface air density, and $\mathbf{V}$ the magnitude of the TC $10 \mathrm{~m}$ winds (Emanuel 2005). The PD is indeed a good proxy of the energy transferred by TCs to surface currents (Vincent et al. $2012 \mathrm{~b}$ ), thus indicating the amount of energy available for ocean mixing. Ekman pumping can be used as a proxy of TC-induced vertical motions. Even though traditional Ekman pumping solution is not valid at the time scale of a TC passage, the thermocline displacement in the aftermath of the storm is similar to the Ekman solution, but with a superimposed inertial oscillation (Gill 1982).

The spatial distribution of the power dissipation and Ekman pumping averaged over the 1983-2007 period are shown in Fig. 1 for the $1 / 2^{\circ}$ resolution used in the present study. The largest PD values are found in the Northwest Pacific (38\% of the global cumulated PD), where the most numerous (30\% of worldwide number) and strongest (34\% of all cyclones of Category 4-5 on the Saffir-Simpson scale) TCs develop. A relatively large PD also characterizes the North East Pacific and South Indian Ocean, with each representing $17 \%$ of the globally cumulated PD. A comparatively smaller amount of TC energy is available in the Southwest Pacific, North Atlantic and Northern Indian Ocean.

The wind structure of an individual TC forces a strong and localised upwelling along its track [within 1 Radius of Maximum Wind (RMW)] compensated by a more modest and widespread downwelling on both sides of the TC innercore footprint (Vincent et al. 2012a, see their Fig. 2b). When averaged annually, the spatial distribution of TC tracks results in a residual Ekman suction (upwelling) in the core of TCs basins and a residual Ekman pumping (downwelling) along their northern and southern flanks (these regions being mainly affected by winds outside the TCs inner-core, Fig. 1b). The residual downwelling signal is also larger on the equatorward side of TC-basins because of the equatorward decrease of the Coriolis parameter. When averaged globally the upward and downward mass transports cancel out, as it is the case for a single storm. 

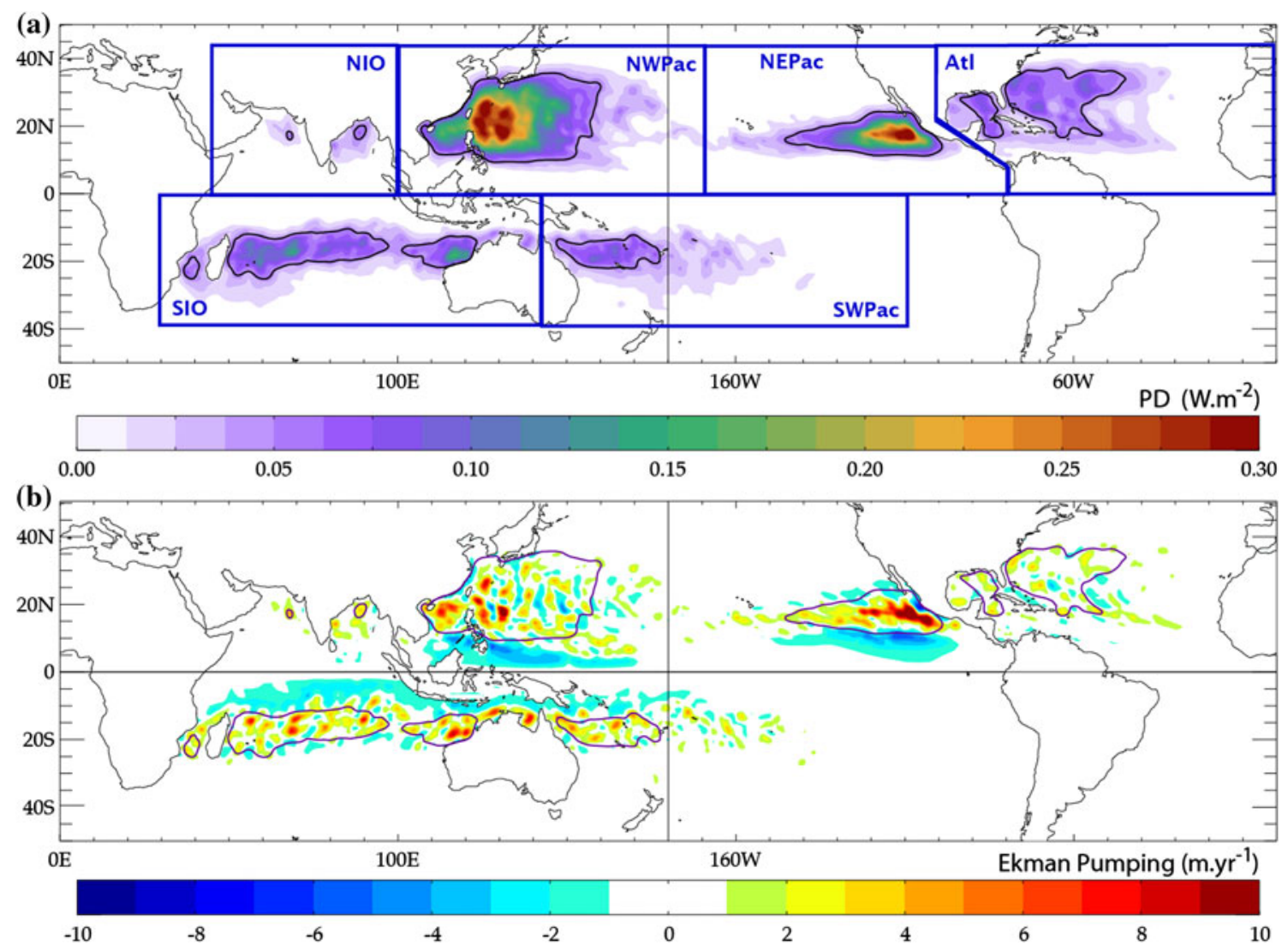

Fig. 1 Mean 1983-2007 tropical cyclone induced a power dissipation ( $\mathrm{PD}, \mathrm{W} \mathrm{m} \mathrm{m}^{-2}$ ), and $\mathbf{b}$ Ekman pumping $\left(\mathrm{m} \mathrm{year}^{-1}\right)$; the superimposed contour is $\mathrm{PD}=0.05 \mathrm{~W} / \mathrm{m}^{2}$. PD is computed from TC winds at the model timestep (36-min) for each point of the model grid and is then yearly averaged to build Fig. 1a. These values are computed on the $1 / 2^{\circ}$ global ORCA mesh, and a $1^{\circ}$ filter is applied in order to highlight the large-scale structure of the curl

ocean response mainly driven by three processes. First, the kinetic energy transferred by the wind stress to surface currents enhances the upper-ocean vertical shear that, in turn, increases vertical mixing. This mixing acts to cool the surface and warm the subsurface waters. Second, the TC wind forcing induces vertical motions (upwelling within 1 RMW of the track and downwelling outside, see Vincent et al. 2012a their Fig. 2), which modify the water column thermal structure through purely adiabatic dynamical processes. Third, the TC wind forcing enhances the surface heat fluxes (mainly through latent heat flux) and thus cools the ocean mixed layer. In order to separate the respective influence of these processes on the TC-induced ocean response, three sensitivity experiments that simulate separately each of these three processes are performed.

To that end, two modifications are introduced online in the three-dimensional (3-D) ocean model: (1) a twin computation of the momentum and heat surface fluxes, so that net forcing accounting or not for TCs wind forcing are simultaneously available $\left(\tau_{T C}, H F_{T C}\right.$ and $\tau_{\text {noTC }}, H F_{\text {noTC }}$ where $\tau$ is the surface wind stress and $H F$ stands for the surface heat fluxes); (2) a twin computation of the vertical 
Table 1 Global mean power dissipation and Ekman upwelling transport of tropical cyclones averaged over the 1983-2007 period as function of model resolution

\begin{tabular}{|c|c|c|c|c|c|}
\hline ORCA mesh resolution & $2^{\circ}$ & $1^{\circ}$ & $1 / 2^{\circ}$ & $1 / 4^{\circ}$ & $1 / 12^{\circ}$ \\
\hline Global mean power dissipation (TW) & 4.48 & 4.47 & 4.49 & 4.50 & 4.62 \\
\hline Global TC-induced upwelling $\left(\mathrm{Sv}=10^{6} \mathrm{~m}^{3} / \mathrm{s}\right)$ & 5.7 & 7.6 & 10.6 & 11.8 & 12.3 \\
\hline
\end{tabular}

These values were computed from the Willoughby et al. (2006) analytical TC wind vortex, applied using IBTrACS TC positions and maximum wind. The space and time sum of TCs upwelling transport is calculated over upward pumping, in order to only cumulate the upwelling induced by each cyclone. Note that the downwelling part calculated in the same way has the same magnitude, so that Ekman pumping cancels out both for a single storm and global mean

mixing coefficients so that two set of mixing coefficients are available, including or not the TC-induced mixing $\left(\kappa_{T C}\right.$ and $\left.\kappa_{n o T C}\right)$. While obtaining a second set for (1) is straightforward, (2) requires a more detailed explanation. We introduced a 1-D model that solves, for each ocean column of the 3-D ocean model, the following linear momentum equation:

$\frac{\partial \mathbf{u}_{1 D}}{\partial t}=-f \mathbf{k} \times \mathbf{u}_{1 D}+\frac{\partial}{\partial z}\left(\kappa \frac{\partial \mathbf{u}_{1 D}}{\partial z}\right)+\left.\frac{\tau}{\rho_{o} \Delta z}\right|_{\text {surface }}$

where $\mathbf{u}_{1 D}$ is the horizontal velocity and $f$ the Coriolis parameter. $\tau$ is the surface wind stress with or without the TC wind forcing. Finally, a vertical mixing coefficient $\kappa$, is computed from a duplication of the TKE turbulent closure. In the TKE equation itself, the surface boundary condition is computed from $\tau_{T C}$ or $\tau_{\text {noTC }}$ resulting in a vertical mixing coefficient $\kappa_{T C}$ or $\kappa_{n o T C}$. The shear TKE production term uses $\mathbf{u}_{1 D}$ and the destruction by stratification term is computed using the 3-D model stratification.

With respect to FILT and CYCL experiments (described in Sect. 2.1), the three sensitivity experiments can be described as follows. The CMIX experiment only accounts for the TC-induced vertical mixing. For this experiment, the 3-D model is forced by $\tau_{\text {noTC }}$ and $H F_{\text {noTC }}$ (i.e. FILT wind forcing) but uses the vertical mixing coefficients provided by the 1-D model forced by CYCL wind forcing $\left(\kappa_{T C}\right)$ under the TC footprint. The CDYN experiment only accounts for the TC-induced ocean dynamical response. In this case, the 3-D model is forced by $\tau_{T C}$ and $H F_{n o T C}$ but uses $\kappa_{\text {noTC }}$ as vertical mixing coefficients along the TC footprints. Finally, CFLX experiment only accounts for the TC-induced heat fluxes. The 3-D model is forced by FILT wind forcing $\left(\tau_{\text {noTC }}\right)$ but uses $H F_{T C}$ under the TC footprints.

\subsection{Significance of TC-induced mean anomalies}

The only difference in the forcing used between the different simulations analysed in this study comes from the TC wind forcing. The only source of noise between two simulations arises from the stochasticity related to mesoscale eddy activity that is only partially resolved in the $1 / 2^{\circ}$ simulation, so that the total noise is very small. It results that all the anomalies related to the TC-induced ocean response discussed in the present study are highly significant. For instance, a two-tailed Student test applied using a reasonable estimate of eddy variability in our model reveals that differences in sea level variations larger than $0.3 \mathrm{~cm}$ are highly significant at $95 \%$ level, making the sea level patterns discussed in Fig. 6 very robust. This holds true for the other variables discussed in the following.

\section{Ocean response at the storm scale}

The purpose of this section is to detail the surface and 3-D processes triggered by TCs under their track before addressing their long-term and large-scale oceanic impact in Sect. 4.

\subsection{3-Dimensional ocean response}

Using FILT and CYCL experiments, Vincent et al. (2012a) investigated the mixed layer processes responsible for the characteristics of TC-induced surface cooling. They show that CYCL reproduces the observed TC cold wake characteristics (amplitude, asymmetry, extent, duration) reasonably well. Since the model also accurately simulates the tropical ocean mean state and variability (Penduff et al. 2010; Lengaigne et al. 2012), this suggests that the mixed layer depth reached during TC passage is reasonably well simulated. The purpose in this subsection is thus not to validate the model against observations, but to illustrate the ability of our numerical strategy to separate the effect of the three main processes (mixing, dynamical response and surface heat fluxes) acting on the ocean thermal structure under a TC.

To that purpose, a composite evolution of the vertical profiles of TC-induced temperature anomalies is computed as the temperature difference between CYCL and FILT experiments underneath TC track positions (Fig. 2). These composites are performed in the vicinity of the TC center (defined as the cross-track average within \pm 2 RMW) and on $T C$ sides (cross-track average between 2 and 8 RMW on both sides of the TC track). The composite is built from every position (at a 6-h resolution) along the tracks of all TCs over the 1983-2007 period. 
The largest oceanic signature underneath TCs center appears as a cold anomaly throughout the water column that last $\sim 30$ days following the TC passage (Fig. 2a). The ocean response on TC sides exhibits a surface cooling overlying a warm anomaly between 30 and $80 \mathrm{~m}$, with no prominent signal at depth (Fig. 2a). The surface cooling disappears within $\sim 2$ months after the TC passage and is replaced by warm anomalies in the top $100 \mathrm{~m}$ both along the TC-track and on the TC sides (Fig. 2a).

The structure and magnitude of these responses can be easily understood in the light of the three sensitivity experiments described in the previous section (Fig. 2b-d). As illustrated on Fig. 2, the total TC-induced ocean response (CYCL experiment) can be largely described as the sum of the TC-induced mixing (CMIX experiment), dynamical processes (CDYN experiment) and heat fluxes (CFLX experiment). Non-linearities ${ }^{1}$ are indeed weak, except below TCs in the top $100 \mathrm{~m}$ for about 20 days where they can reach $25 \%$ of the total signal (Fig. 2e vs. a). This non-linearity near the surface is likely to result from the overestimation of cooling induced by heat fluxes in CFLX experiment: surface fluxes under TCs are enhanced in this experiment compared to CYCL because it does not include the cooling induced by mixing and advection. These weak non-linearities suggest that our modeling strategy allows identifying unambiguously the first-order contribution of each process to the model ocean response.

Both TC-induced heat fluxes (Fig. 2b) and vertical mixing (Fig. 2d) strongly contribute to the surface cooling simulated both under and further away from TC track, in agreement with Vincent et al. (2012a). This large-scale cooling vanishes in $\sim 40$ days after the TC passage for both experiments. In CFLX, the surface cooling is damped by atmospheric heat fluxes. In CMIX, as TC-induced mixing warms the 30-100 m sub-surface layer (Fig. 2b), both entrainment of these mixing-induced warm sub-surface anomalies into the mixed layer and heat fluxes contribute to damp the surface cooling. The entrainment of these warm subsurface anomalies further results in a slight SST warming after $\sim 60$ days that persists beyond 100 days after the cyclone passage. Finally, the cooling signal simulated at depth under the TC track (Fig. 2a) is related to the net upwelling vertical velocity driven by the TC-induced divergent surface Ekman flow (Fig. 2c) in agreement with Scoccimarro et al. (2011) results (see their Fig. 9).

\footnotetext{
1 The differences between CYCL and CMIX + CDYN + CFLX also includes the shear production associated to horizontal density gradients generated by TCs which are not accounted for in the 1D momentum equation. This shear production has however been diagnosed to be negligible.
}

Another remarkable feature of the local response to TCs, first described by Jansen et al. (2010), is the westward propagation of these TC-induced upwelling signals. These authors used the observed sea level anomalies (SLA; their Fig. 2) depression in the center of the TC wake as an integrated signature of the water column cooling. Replicating Jansen et al. (2010) analysis allows validating this propagating feature in the model. As shown on Fig. 3, the model reproduces the main characteristics of this propagation of TC-induced SLA. The residual TC-induced upwelling results in a sea level anomaly that propagates westward at a speed of $0.1 \%$ day $(\approx 0.1 \mathrm{~m} / \mathrm{s})$ in both datasets. While the SLA amplitude closely agrees 1 month after TC passage, it is larger in the model than in observations one week after the TC passage. Although model deficiencies cannot be discarded, we argue that satellite observation's poor spatial and temporal sampling of the TC response may partly explain this mismatch for the fast evolving anomalies under the TC. Conversely, the 'longlived' residual large scale SLA signal 1 month after TC passage could be more accurately captured by satellite observations. We will show that this westward SLA propagation is important to explain the TC-induced impact on the ocean climatology discussed in Sect. 4.1.

\subsection{Surface ocean response}

The purpose of this subsection is to describe the SST, mixed layer depth (MLD) and heat flux evolution beneath the TC, not only during the TC passage but also later in their wake, a necessary step to explain the climatic impact of TCs in the next section.

As a TC translates over a given ocean location, the SST drops as a result of the three main processes presented in the previous section. The maximum cooling $\left(\sim 1.4{ }^{\circ} \mathrm{C}\right)$ is observed 1-2 days after the TC passage (Fig. 4a), in agreement with observations as discussed in Vincent et al. (2012a). This cooling occurs in conjunction with a mixed layer deepening (Fig. 4b). During this period (about days -4 to days +2 ), TC winds extract heat from the ocean through enhanced enthalpy fluxes used to fuel the TC heatengine (Emanuel 1986) (Fig. 4c).

The cold surface temperature anomaly left in the TCs' wake is then damped by atmospheric fluxes in the months following the TC passage, inducing an oceanic heat uptake (i.e. a net surface heat transfer into the ocean) from a few days after to $\sim 80$ days after the TC passage (Fig. $4 \mathrm{c}$ ). As noticed by Park et al. (2011) in their analysis of ARGO profilers data, the oceanic heat uptake lasts slightly longer than the typical surface temperature anomaly decay time scale found in satellite observations (Price et al. 2008) and in the CYCL experiment (Vincent et al. 2012a). The mixed layer depth evolution allows explaining this feature. The 

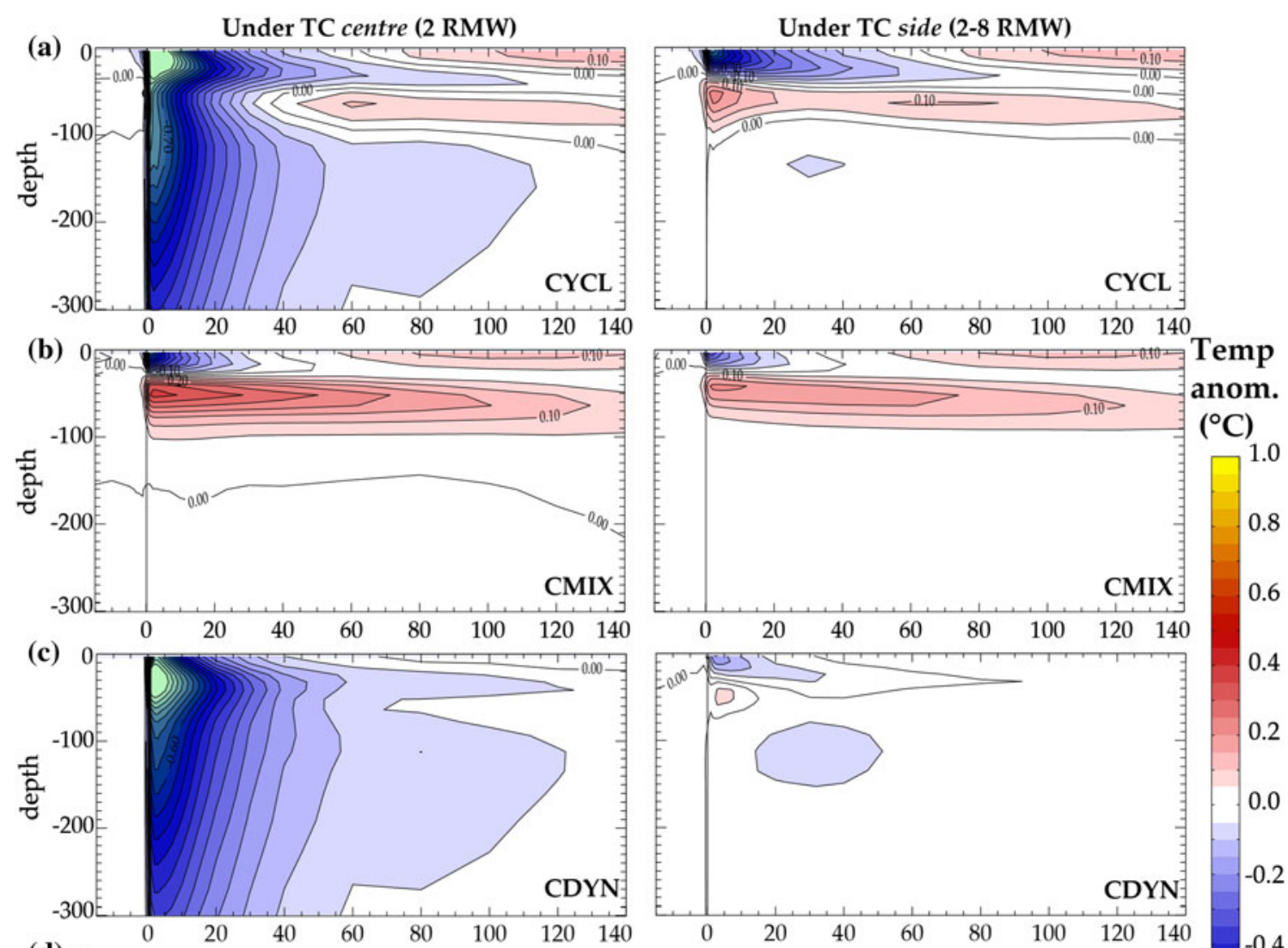

anom.

$\left({ }^{\circ} \mathrm{C}\right)$
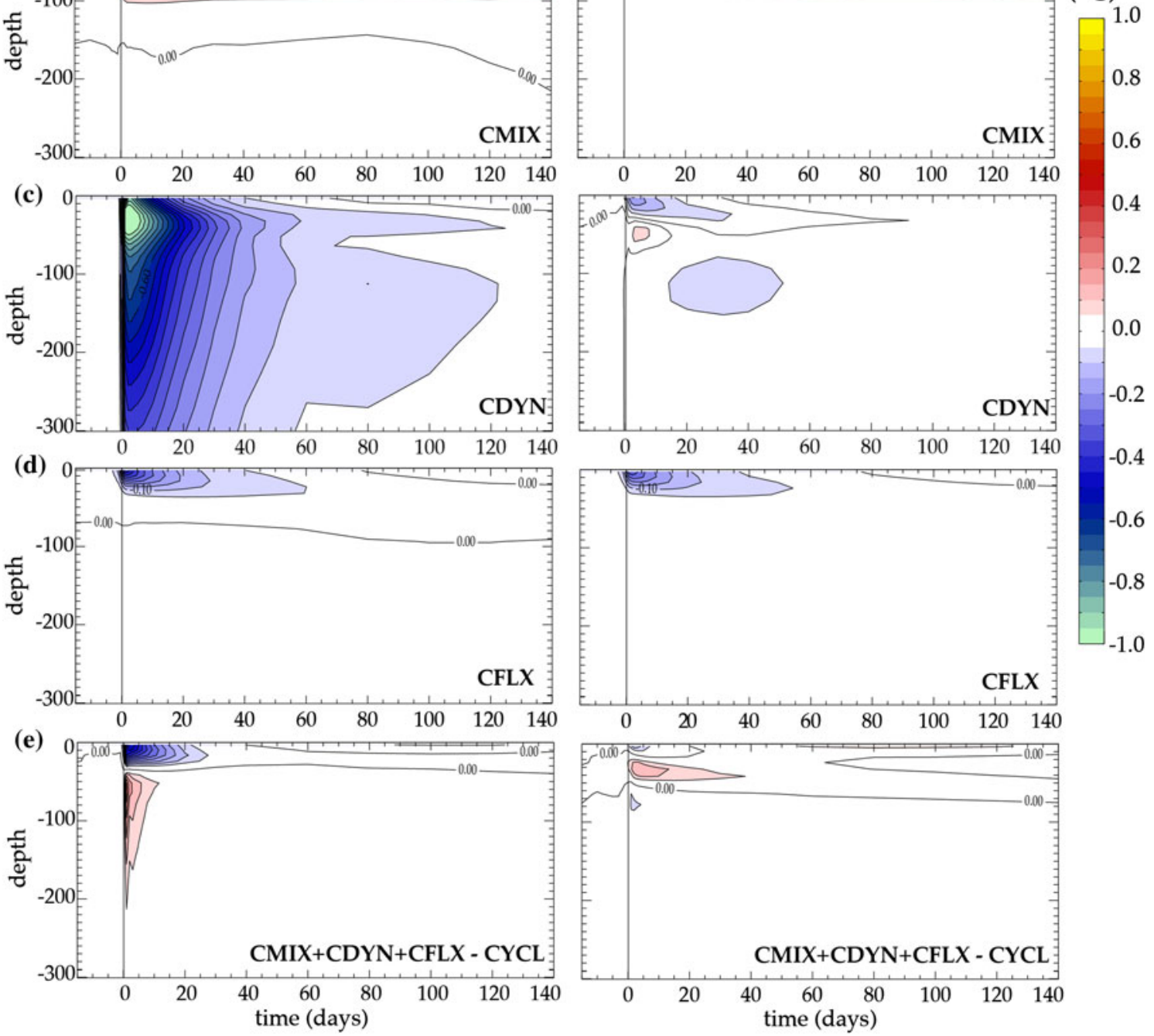

Fig. 2 Depth-time composite of temperature anomalies relative to the FILT experiment for experiments a CYCL (total effect of the TC), b CMIX (TC-induced mixing), c CDYN (TC-induced dynamical response), d CFLX (TC-induced fluxes), and e the difference $($ CMIX + CDYN + CFLX) - CYCL (non-linearities), (left) within

storm passage induces a deepening of the mixed layer (Fig. 4b) and a strong cooling in the top $40 \mathrm{~m}$ (Figs. 2a, 4a). Just after the TC passage, the ocean quickly restratifies and the mixed layer shallows (Fig. 4b) so that cold surface anomalies vanish quicker than cold anomalies just below

2 Radii of Maximum Wind (RMW) of the TC-center and (right) on the TC-sides (within 2-8 RMW of the cyclone track). The composite encompasses all TCs with 10-min sustained wind speed greater than $15 \mathrm{~m} \mathrm{~s}^{-1}$ during the 1983-2007 period

the mixed layer (Fig. 2a). Then, after $\sim 60$ days, as the mixed layer deepens in fall, remnant cold anomalies left just below the mixed layer from the TC passage are re-entrained in the mixed layer. The resulting ML cooling induces compensating heat fluxes into the ocean, 
Fig. 3 Composite hovmöller diagram (longitude-time) of the sea level anomaly $(\mathrm{cm})$ response to the tropical cyclone passage. The composite gathers all poleward-propagating TCs with maximum 10-min sustained winds exceeding $15 \mathrm{~m} \mathrm{~s}^{-1}$ for the time period 1998-2006. Anomalies are calculated relative to the values before the passage of the storm (day -15 to day -5 ) and the seasonal cycle is removed. a Observed SLA from AVISO weekly $1 / 3^{\circ}$ product, and b CYCL weekly averaged SLA fields

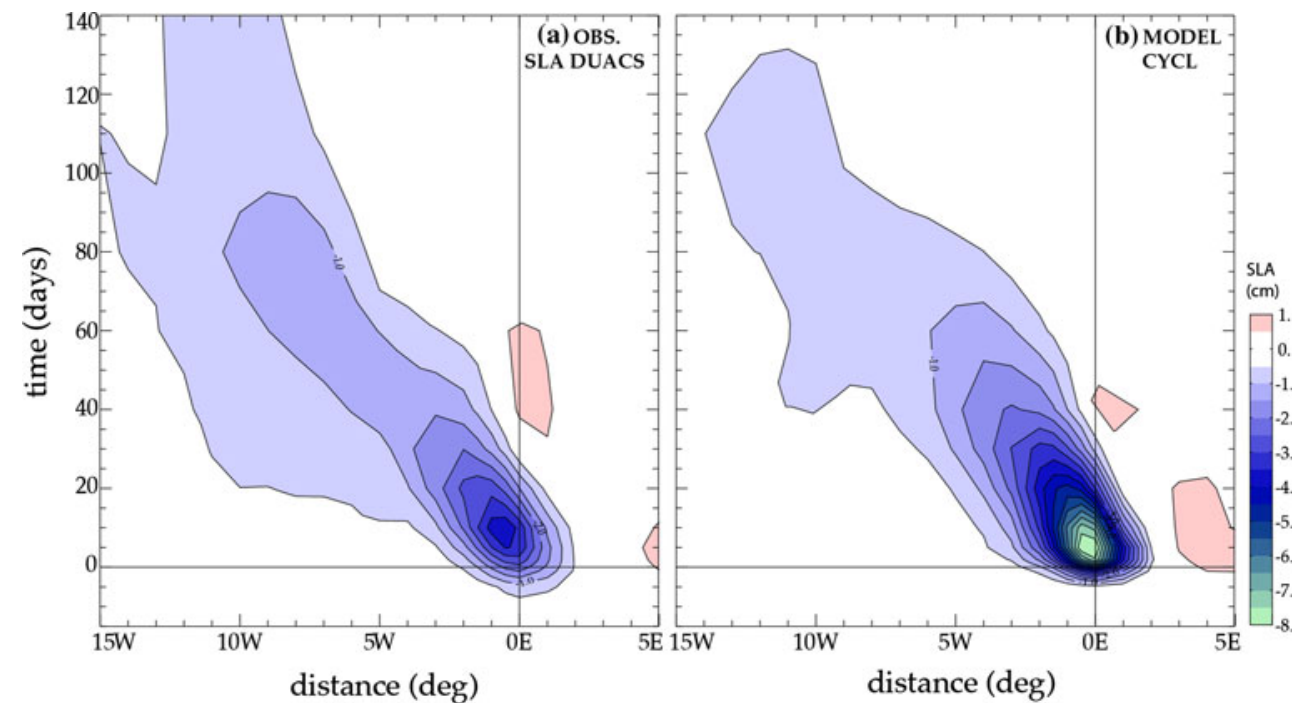

explaining the long-lasting ocean heat uptake displayed on Fig. 4c. Finally, as ML continues to deepen in fall, subsurface warm anomalies are further entrained into the ML and the SST becomes warmer in the CYCL run than in FILT (Fig. 4a). As a result, heat flux anomalies become negative again after $\sim 80$ days when heat stored in the subsurface layers is released back to the atmosphere.

\section{Climatological impact of TCs on the ocean}

\subsection{Annual mean oceanic response to tropical cyclones}

Figure 5 shows TC-induced long-term mean temperature changes averaged over three oceanic layers $(0-30,30-100$ and $100-400 \mathrm{~m}$ ), selected on the basis of the vertical extents of the TC-response in Fig. 2.

TCs trigger a climatological cooling of the upper-oceanic layer in TC-prone regions (i.e. where PD is large, see Fig. 5a) with a magnitude roughly proportional to the mean TC wind power (Vincent et al. 2012b). The largest cooling is found in the Northwest and Northeast Pacific basins $\left(-0.5^{\circ} \mathrm{C}\right)$. The TC-induced climatological cooling hardly reaches $-0.2{ }^{\circ} \mathrm{C}$ in the South Indian Ocean, and $-0.1{ }^{\circ} \mathrm{C}$ in the Southwest Pacific and Atlantic basins. Modest warm anomalies $\left(<0.1{ }^{\circ} \mathrm{C}\right)$ are also found poleward of the main TC-basins as well as in the eastern equatorial Pacific. A local strong warming $\left(\sim 0.7^{\circ} \mathrm{C}\right)$ occurs along the California coast and will be discussed later on.

All TC-basins exhibit a subsurface warm anomaly in the intermediate layer (30-100 m) shifted poleward of the regions of maximum surface cooling (Fig. 5b). Strongest warming are found in the North Pacific Ocean (up to $1{ }^{\circ} \mathrm{C}$ in the Northeast Pacific and $0.7^{\circ} \mathrm{C}$ in the Northwest Pacific) while those warm anomalies do not exceed $0.2{ }^{\circ} \mathrm{C}$ in other TC-basins. The equatorial strip is characterized by a $0.1{ }^{\circ} \mathrm{C}$ warming in the Indian Ocean and eastern Pacific Ocean, and a stronger $0.5{ }^{\circ} \mathrm{C}$ warming just south of the Northeast Pacific TC-basin. Finally, the deeper layer $(100-400 \mathrm{~m})$ is characterized by zonally distributed anomalies of alternating signs, with cooling in the core of TC basins and warming on their poleward and equatorward flanks (except in South Indian Ocean where a deep cold anomaly is observed around the equator).

Figures 6 and 7 display respectively the TC-induced climatological sea surface height (SSH) and sea surface temperature (SST) changes and the relative contribution of cyclone-induced mixing, surface fluxes and dynamical response to the total anomalies. Figure 8 shows corresponding temperature latitude-depth sections across the Northwest Pacific and South Indian Ocean basins. For the sake of concision, regional aspects of the ocean response to TCs are only illustrated for these two sub-basins; other basins response, not detailed in the present paper, however shows very similar behaviour. As for the local response to TCs, non-linearities are negligible everywhere, except in regions of strongest SST cooling (Figs. 6e, 7e). As discussed in Sect. 3.1, this feature results from the overestimation of the heat fluxes extracted under TCs in CFLX experiment, due to the absence of surface cooling by mixing and upwelling.

SSH anomalies shown on Fig. 6 integrate the signature of the three oceanic layers depicted in Fig. 5. TC-induced upwelling and downwelling signals driven by the dynamical response isolated in CDYN experiment dominates the climatological SSH response (Fig. 6c). In the Northeast Pacific, the residual climatological TC-induced Ekman upwelling around $\sim 15^{\circ} \mathrm{N}$ (Fig. 1b) shifts the thermocline upward, resulting in a negative SSH anomaly in this region. The opposite occurs on the northern and southern flanks of 

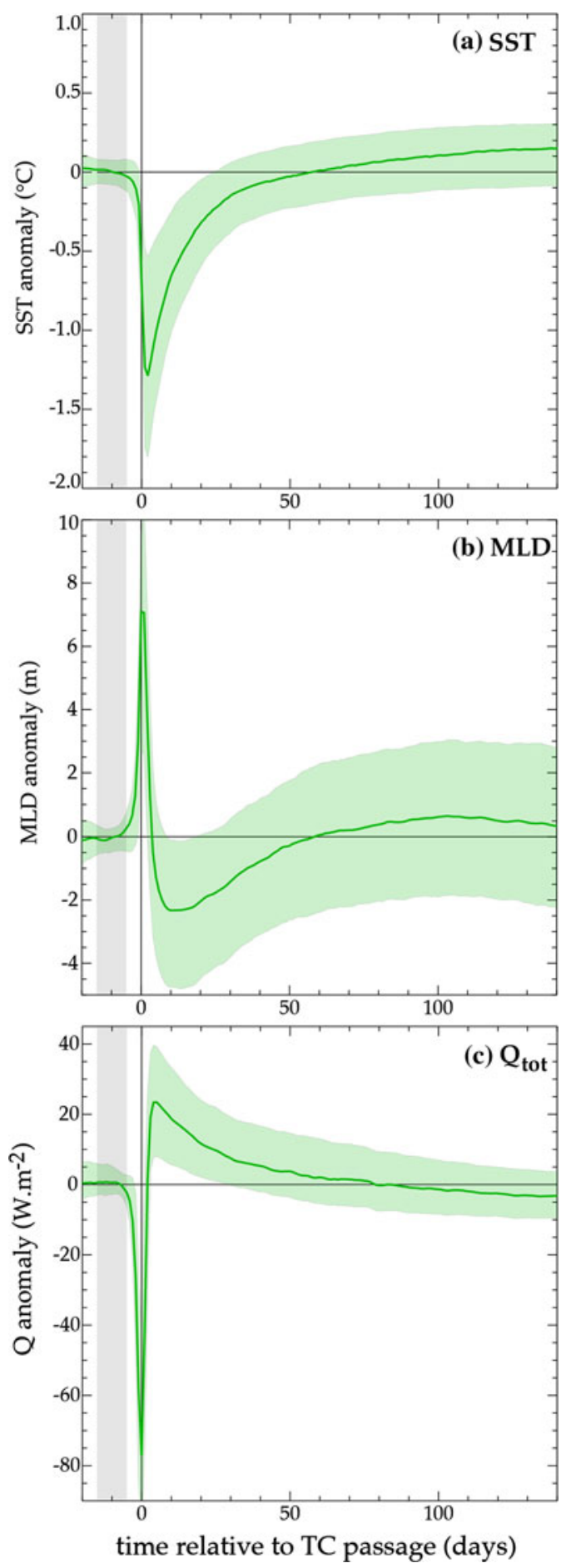

Fig. 4 Composite time series of a sea surface temperature (SST; in ${ }^{\circ} \mathrm{C}$ ), b mixed layer depth (MLD; in m) and $\mathbf{c}$ total surface flux ( $\mathrm{Q}_{\text {tot }}$; positive toward the ocean, in $\mathrm{W} \mathrm{m}^{-2}$ ) anomalies generated by TCs in the CYCL experiment relative to FILT. MLD and SST anomalies are averaged within $200 \mathrm{~km}$ of the center of the storms (as in Vincent et al. 2012a). $\mathrm{Q}_{\text {tot }}$ is averaged within $600 \mathrm{~km}$ of the center of the storms to account for the whole area where we explicitly represent the TC winds. The composite gathers all TCs with 10-min sustained wind speed greater than $15 \mathrm{~m} \mathrm{~s}^{-1}$ over the 1983-2007 period. Shading indicates the spread around the mean value, evaluated from the lower and upper quartiles
TC basins where residual climatological TC-induced Ekman downwelling dominates (Fig. 1b), resulting in a positive SSH anomaly. These thermocline anomalies then propagate westward as a result of planetary wave dynamics (Fig. 3; Jansen et al. 2010) and hence expand zonally to affect the entire North Pacific. These SSH anomalies signals are reinforced in the western part of the basin due to local Ekman pumping in the Northwest Pacific. The other TC-prone basins exhibit similar zonally oriented structures of negative SSH anomalies in the latitude bands of maximum cyclonic activity (Fig. 6c). TCinduced dynamical ocean response is also largely responsible for the sea level rise in the equatorial eastern Pacific and the associated warm surface and sub-surface equatorial anomaly seen on Fig. 5. TC-induced vertical mixing is the second largest contributor to TC-induced SSH anomalies. Mixing injects warm water down below the mixed layer in TC-prone regions while surface cooling is cancelled by surface fluxes, resulting in a positive SSH anomaly. This rise is largest in the Northwest $(0.9 \mathrm{~cm})$ and Northeast Pacific $(0.6 \mathrm{~cm})$ while it only reaches $\sim 0.1 \mathrm{~cm}$ in other TCs basins. All TC-induced SSH anomalies are small with respect to large scale $\mathrm{SSH}$ variations $(\sim 1 \mathrm{~m})$.

In contrast to sea level, TC-induced heat fluxes are the major contributor to the basin-wide sea surface cooling (Fig. 7). TC-induced vertical mixing (Fig. 7b) cools the ocean surface in the core of TC basins. TC dynamical response (Fig. 7c) slightly cools the SST in TC-induced upwelling areas (by $\sim 0.1^{\circ} \mathrm{C}$ ), except in the Northeast Pacific where the shallow thermocline allows a larger surface cooling $\left(\sim 0.3^{\circ} \mathrm{C}\right)$, comparable to the effect of TCinduced air-sea fluxes and mixing. The TC-induced dynamical response also warms the ocean surface on the poleward flank of TC-basins by deepening the thermocline, hence reducing surface cooling by entrainment. The strong warming along the California coast is driven by the TCinduced dynamical response (Fig. 7c). In this region, tropical storms are known to be a major driver of SLA intraseasonal variability (Enfield and Allen 1983). In this region, TCs usually travel northward along the coast, favoring a coastal downwelling signal and resulting in positive SSH anomalies. These anomalies then propagate northward as coastally trapped Kelvin Waves, and warm the ocean surface.

Finally, meridional temperature sections shown on Fig. 8 allow summarizing the salient features of the mean vertical ocean response to TCs forcing. TCs forcing is responsible for:

(i) an intense subsurface warming around $20^{\circ}-30^{\circ}$ : this warming is maximum at $50 \mathrm{~m}$ depth, reaching $0.4{ }^{\circ} \mathrm{C}$ in the Northwest Pacific. At this depth, warming 

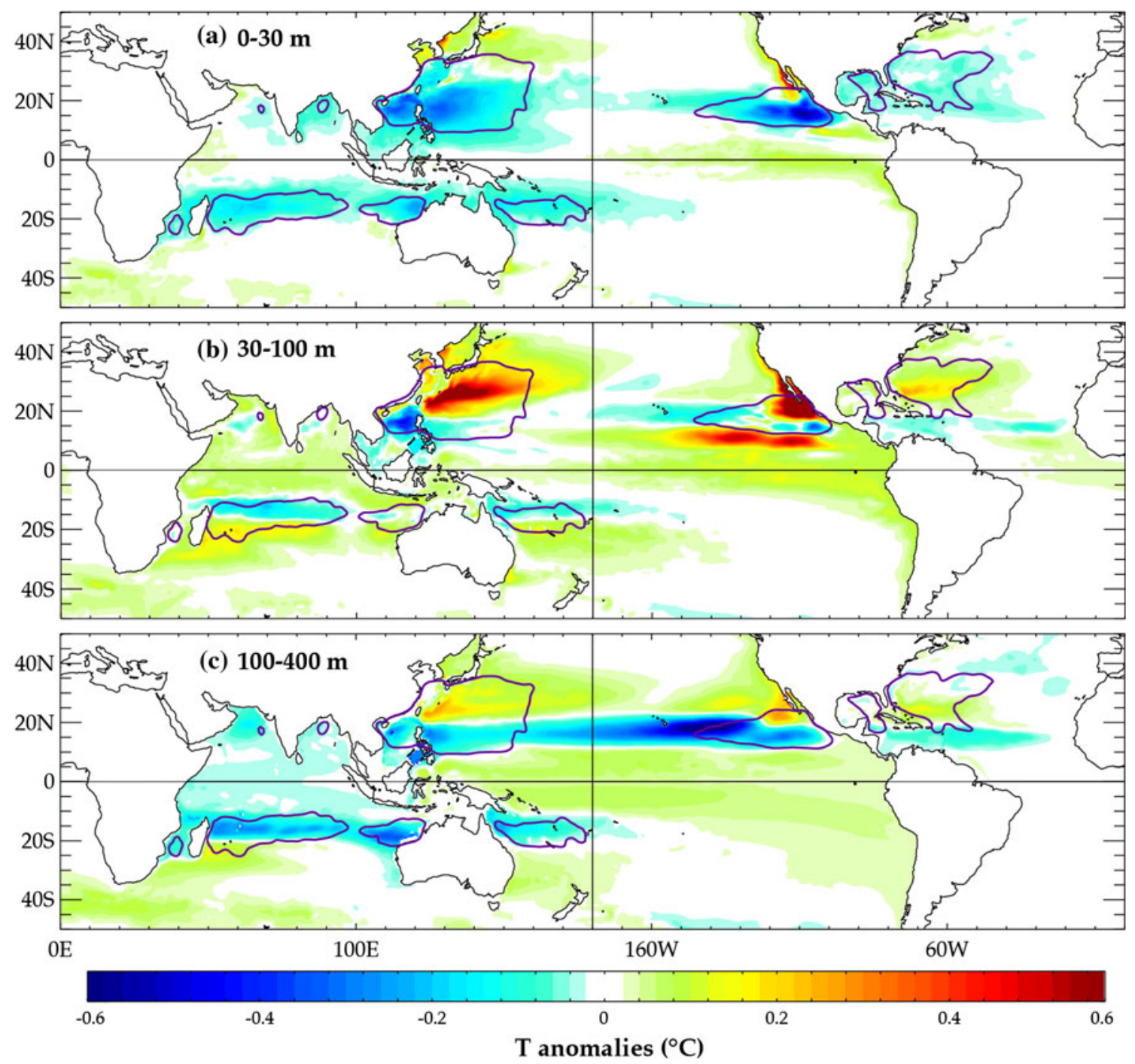

Fig. 5 Mean 1983-2007 TC-induced temperature anomalies $\left({ }^{\circ} \mathrm{C}\right)$ averaged over a the surface layer $(0-30 \mathrm{~m})$, b the $30-100 \mathrm{~m}$ layer, and $\mathbf{c}$ the $100-400 \mathrm{~m}$ layer. The purple contour delineates regions of intense TC activity $\left(\mathrm{PD}=0.05 \mathrm{~W} / \mathrm{m}^{2}\right.$, see Fig. 1$)$

largely results from TC-induced mixing. From $50 \mathrm{~m}$ down to $300 \mathrm{~m}$, TC-induced downwelling also contributes to this warming.

(ii) an intense cooling of the whole water column centered around $15^{\circ}$ : TC-induced upwelling is largely responsible for this cooling at depth while mixinginduced warming and upwelling-induced cooling almost entirely cancel each other around $100 \mathrm{~m}$ depth. In the surface layers, the three processes work together to produce a persistent surface cooling, with TC-induced air-sea fluxes being the dominant process.

(iii) a warming in the equatorial $\left(10^{\circ} \mathrm{S}-10^{\circ} \mathrm{N}\right)$ thermocline due to TCs wind: this signal results from both TC-induced downwelling and subsurface equatorward advection of mixing-induced warm anomalies (Fig. 6b).

\subsection{Seasonality of ocean response to TCs}

The annual mean values discussed in the previous subsection mask the contrasted seasonal impact of TCs. TCs are indeed mainly active during local summer, with a maximum activity between July and October in the northern hemisphere and December to March in the southern hemisphere. Figure 9 displays a depth-latitude section of TC-induced temperature anomalies in the Northwest Pacific and South Indian Ocean basins during these two seasons. In both basins, cold surface anomalies are about twice stronger and warm sub-surface TC-induced anomalies are about $50 \%$ stronger during cyclonic seasons than on annual average (Figs. 8, 9), with largest warm subsurface anomalies located in the seasonal thermocline. During local winter, most of the surface layer cooling vanishes, while the warm subsurface anomaly considerably 
Fig. 6 Mean 1983-2007 sea surface height anomalies (cm) relative to FILT experiment for a CYCL (total effect of the TC), b CMIX (TC-induced mixing), c CDYN (TC-induced dynamical response), d CFLX (TC induced fluxes), and e the difference

$(\mathrm{CMIX}+\mathrm{CDYN}+\mathrm{CFLX})-$ CYCL (non-linearities). Purplecontour reminds the regions of intense TC activity $\left(\mathrm{PD}=0.05 \mathrm{~W} / \mathrm{m}^{2}\right)$. All anomalies shown as color shading are significant at the $95 \%$ confidence level
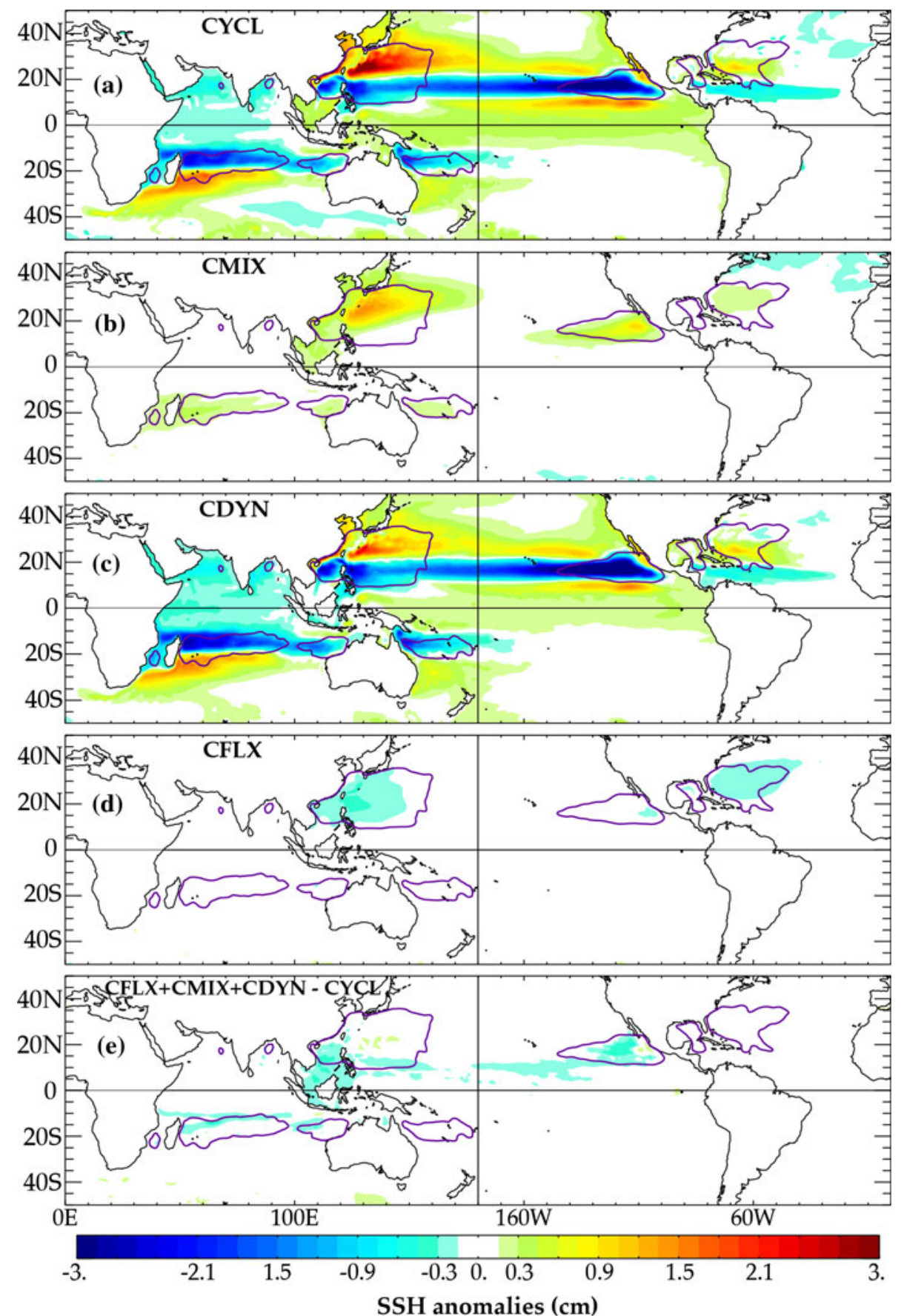

weakens and extends up to the surface. Anomalies located deeper than the seasonal thermocline persist all year long.

This seasonal behavior can be understood as follows. TCs primarily occur during summer and early fall, when the ocean mixed layer is generally shallow and lies above a seasonal thermocline. TC-related mixing hence acts to cool the ocean surface and warm the seasonal thermocline. As the mixed layer deepens the following winter, most of the heat anomalies deposited within the seasonal thermocline during the TC-season are re-entrained into the mixed layer.
This results in a SST warming in the heart of TC-basins during the TC-inactive season (local winter), when heat is released back to the atmosphere. Only the deepest part of the warm anomalies deposited in the main thermocline during the TC-season is able to persist through winter (Jansen et al. 2010).

This seasonal TC-induced buffering effect has a significant impact on the amplitude of the SST seasonal cycle. TC-induced SST anomalies during TC-seasons in each hemisphere are displayed on Fig. 10. Summer seasons are 
Fig. 7 Mean 1983-2007 sea surface temperature anomalies $\left({ }^{\circ} \mathrm{C}\right)$ relative to FILT experiment for a CYCL (total effect of the TC), b CMIX (TCinduced mixing), $\mathbf{c}$ CDYN (TCinduced dynamical response), d CFLX (TC induced fluxes), and $\mathbf{e}$ the difference (CMIX + CDYN + CFLX) CYCL (non-linearities). Purplecontour reminds the regions of intense TC activity $\left(\mathrm{PD}=0.05 \mathrm{~W} / \mathrm{m}^{2}\right)$
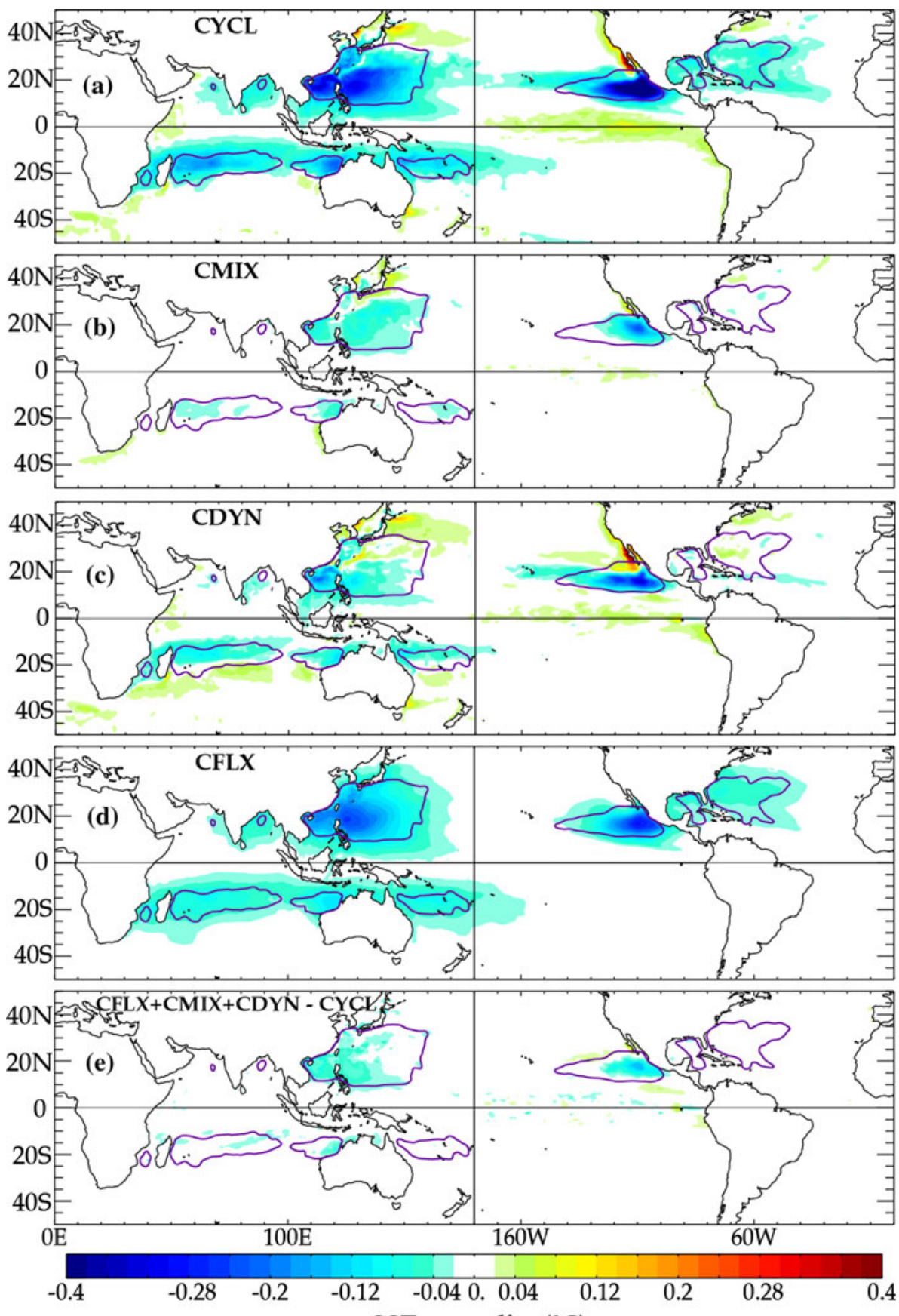

characterized by widespread cooling in TC-prone regions while winter seasons mainly exhibit warm anomalies. These surface anomalies are particularly large in regions where TCs are most frequent (Northwest and Northeast Pacific; compare Figs. 1 and 10). For instance, the Northwest Pacific SST anomaly reaches $-0.7{ }^{\circ} \mathrm{C}$ during summer and becomes positive during winter, reaching $+0.4{ }^{\circ} \mathrm{C}$ in regions of maximum subsurface warming (Figs. 5b, 10b). The effect of TCs is to cool the ocean surface during summer and to slightly warm it during winter, and thus TCs act to reduce the SST seasonal cycle.
The seasonal cycle amplitude can be diagnosed as the SST difference between the warmest and coldest months in the monthly mean seasonal cycle (Fig. 11a). The TCinduced reduction of the SST seasonal cycle can then be computed as the difference of this seasonal cycle amplitude in the CYCL and FILT experiments (Fig. 11b). TCs act to reduce the seasonal cycle equatorward of $30^{\circ}$ in both hemispheres. This reduction reaches $\sim 0.5{ }^{\circ} \mathrm{C}$ in the Southern hemisphere and more than $1{ }^{\circ} \mathrm{C}$ in the Northern hemisphere and corresponds to a 5-15\% decrease of the seasonal cycle amplitude in most of the 
Fig. 8 Latitude-depth zonal averaged 1983-2007 temperature anomalies $\left({ }^{\circ} \mathrm{C}\right)$ relative to FILT experiment for (left) Northwest Pacific and (right) Indian Ocean basins. From top to bottom: CYCL (total effect of the TC), CMIX (TC-induced mixing), CDYN (TC-induced dynamical response), CFLX (TC induced fluxes). These sections are zonally averaged between $120^{\circ} \mathrm{E}$ and $170^{\circ} \mathrm{E}$ for the NW Pacific basin and between $50^{\circ} \mathrm{E}$ and $100^{\circ} \mathrm{E}$ for the Indian Ocean basin. The difference $(\mathrm{CMIX}+\mathrm{CDYN}+\mathrm{CFLX})-$ CYCL (non linearities) is very weak and thus not shown
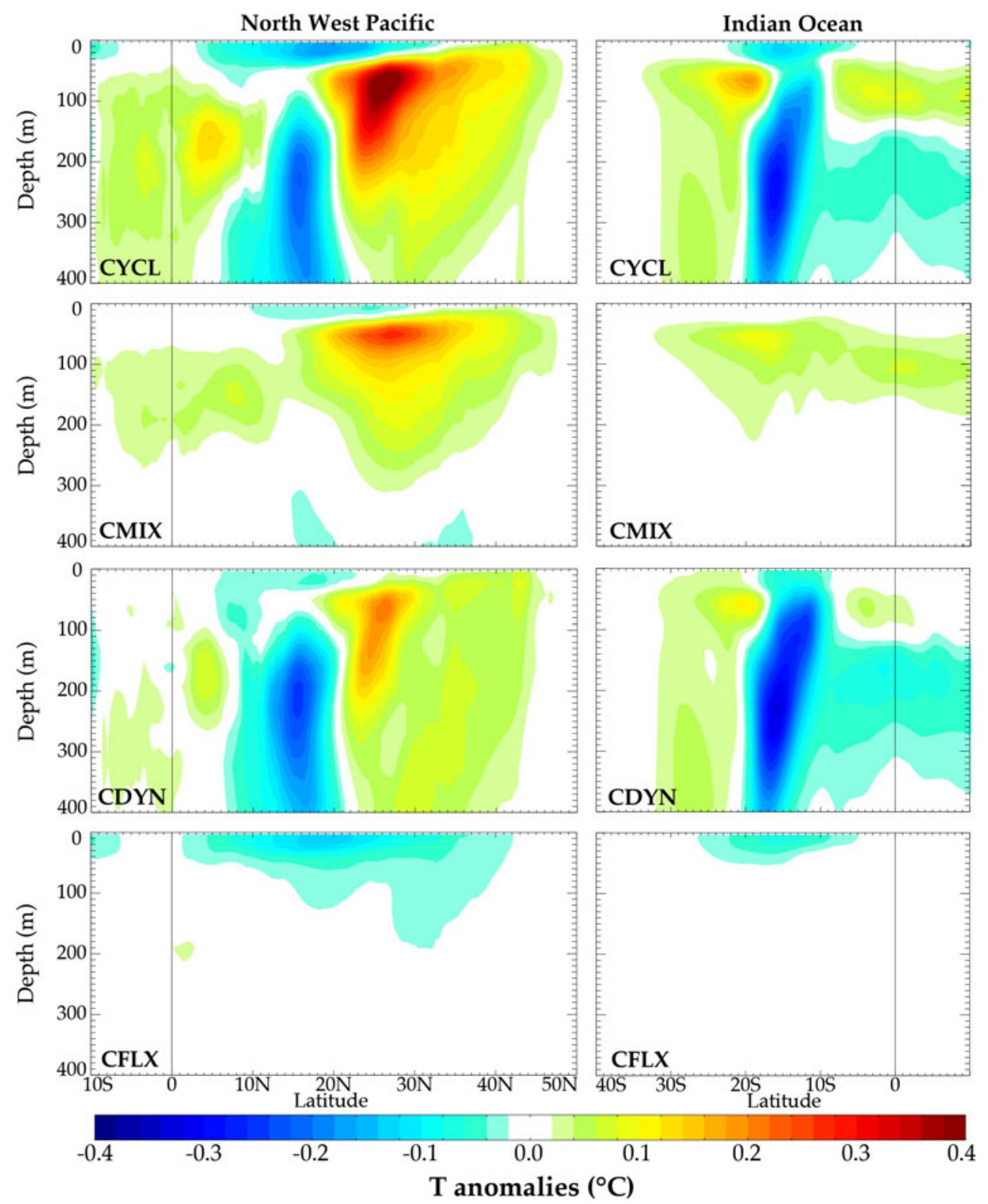

TC basins, except in the Northeast Pacific where it reaches up to $30 \%$.

\subsection{TC-induced ocean heat uptake and transport}

This subsection aims at quantifying and understanding the TC-induced change in surface fluxes and the associated oceanic heat transport required to balance them. As discussed in Sect. 3.2, there are three typical phases associated with a cyclone passage (Fig. 12a): a strong oceanheat extraction (OHE, yellow area on Fig. 12a) during the cyclone passage (i.e. the strong enthalpy fluxes under the TC associated to its intense winds), followed by an oceanheat uptake (OHU, red area on Fig. 12a) i.e., positive heat fluxes into the ocean in response to the cold SST in the
TC wake, and finally an oceanheat release (OHR, blue area on Fig. 12a) associated with the re-emergence of the subsurface warm anomalies during the following fall/winter and associated positive heat flux toward the atmosphere.

Note that this definition of the Ocean Heat Uptake (OHU) is identical to the one used by previous authors (e.g. Emanuel 2001; Sriver et al. 2008; Jansen et al. 2010). While some authors (Jansen et al. 2010) took into account the fact that the OHU was partially canceled by the OHR (i.e. the heat released back to the atmosphere during the next season), no study took the OHE into account, i.e. the fact that the amount of heat flux toward the atmosphere extracted during the TC passage partially compensates the OHU. Below, we explain how we estimate all these quantities. 

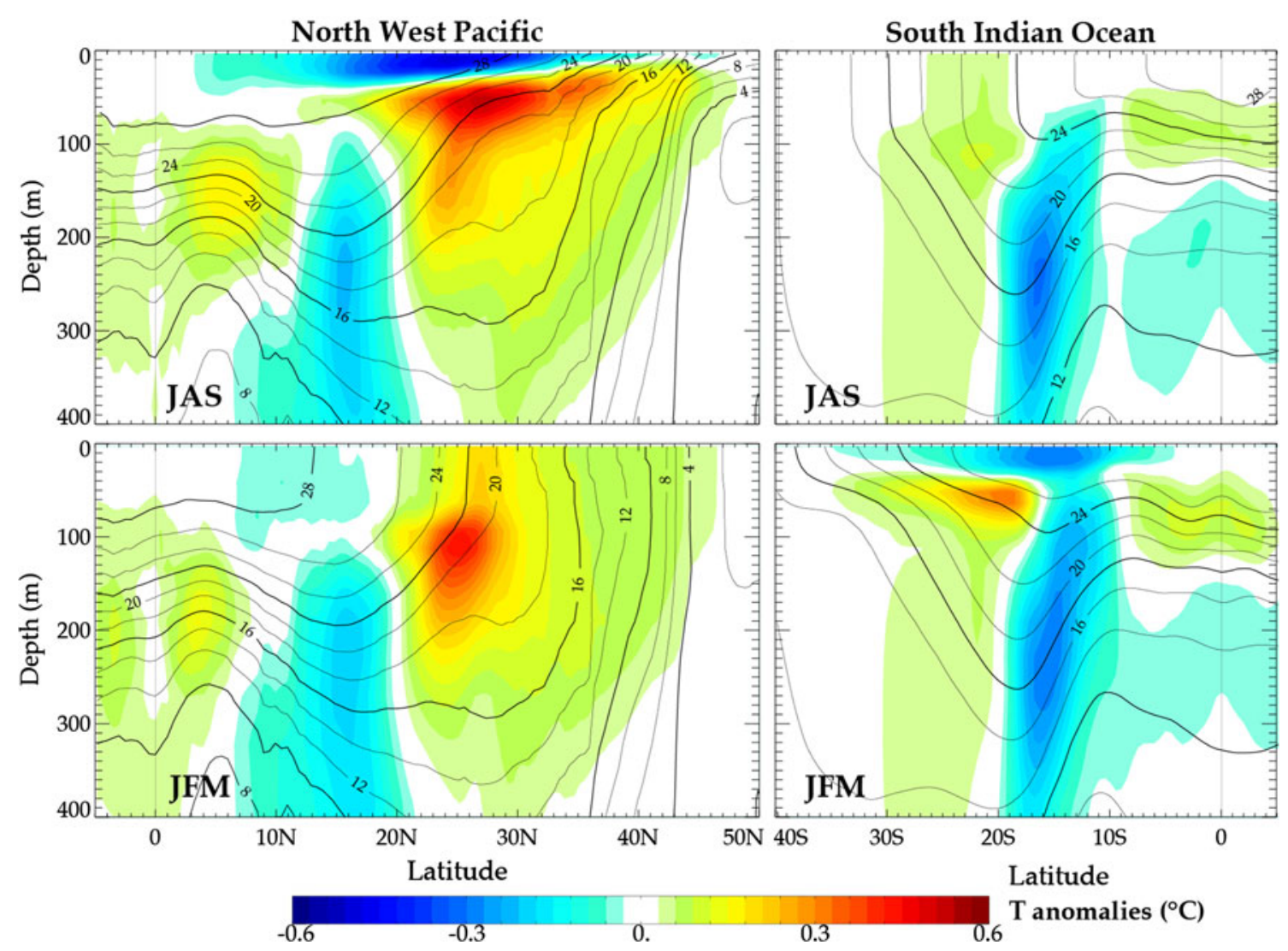

Fig. 9 Mean 1983-2007 temperature $\left({ }^{\circ} \mathrm{C}\right.$; contour $)$ and temperature anomalies $\left({ }^{\circ} \mathrm{C}\right.$; shading) in (left) Northwest Pacific and (right) Indian Ocean basins during (top) the Northern Hemisphere cyclonic season (July to September) and (bottom) during the Southern Hemisphere cyclonic season (January to March). These sections are zonally

averaged between $120^{\circ} \mathrm{E}$ and $170^{\circ} \mathrm{E}$ for the NW Pacific basin and between $50^{\circ} \mathrm{E}$ and $100^{\circ} \mathrm{E}$ for the Indian Ocean basin. Note that the maximum sub-surface warm anomalies during TC seasons are located in the seasonal thermocline

Fig. 10 Mean 1983-2007 CYCL SST anomalies $\left({ }^{\circ} \mathrm{C}\right)$ relative to the FILT experiment for $\mathbf{a}$ the northern and $\mathbf{b}$ the southern hemisphere TCseasons (July to September and January to March, respectively)
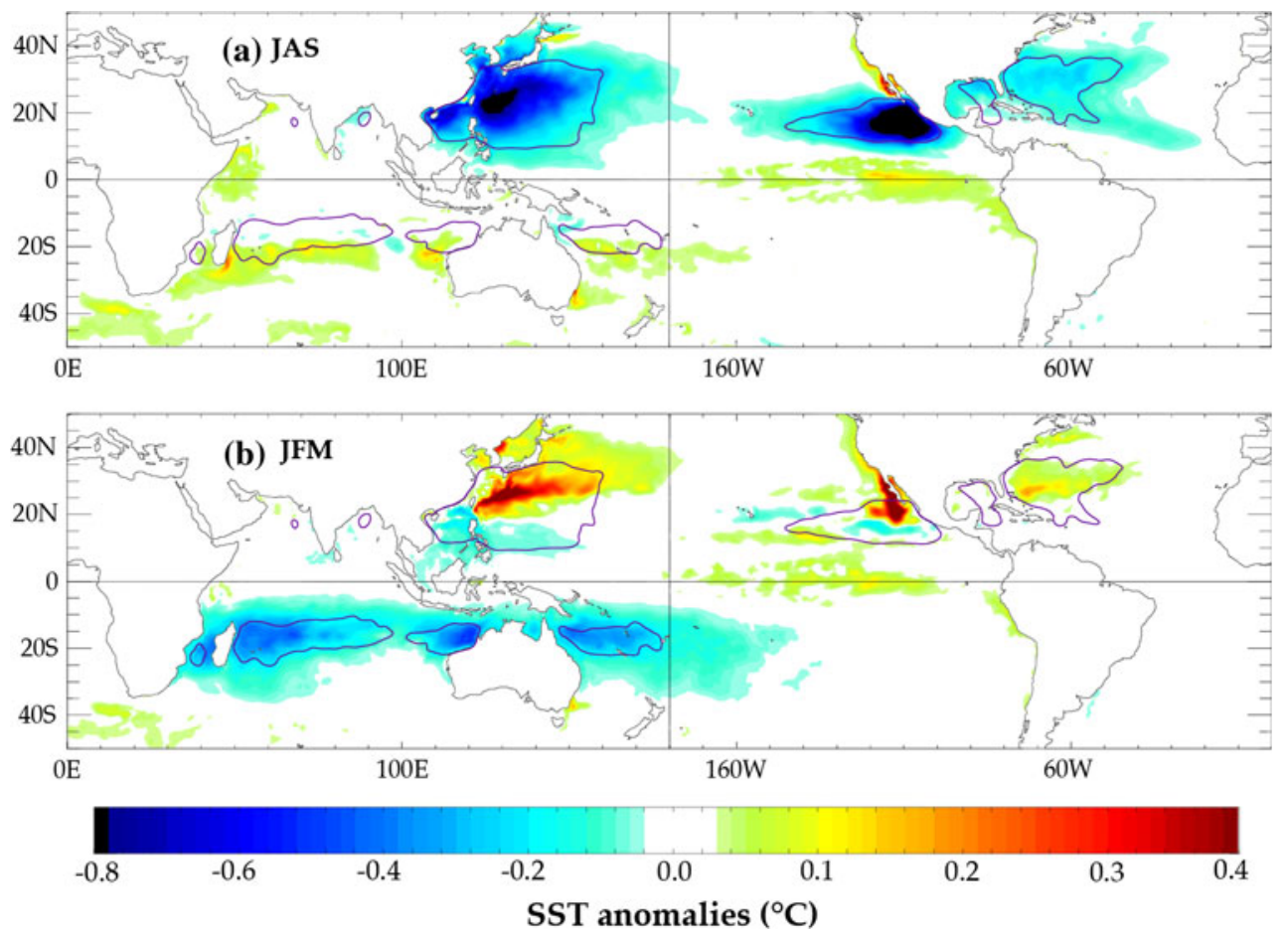
Fig. 11 a Mean 1983-2007 CYCL SST $\left({ }^{\circ} \mathrm{C}\right)$ seasonal cycle amplitude (max-min on 12-month SST) and $\mathbf{b}$ its anomalies relative to FILT experiment
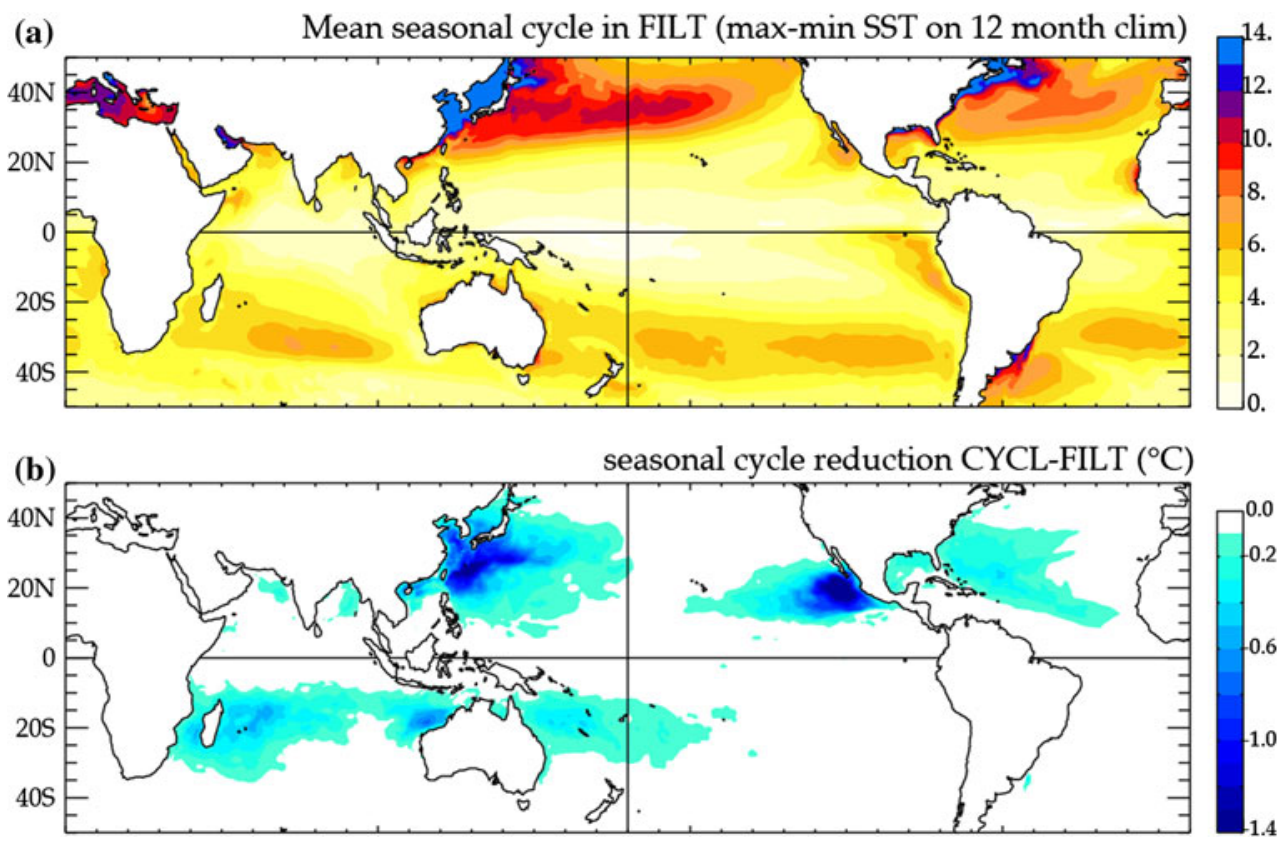

(a)

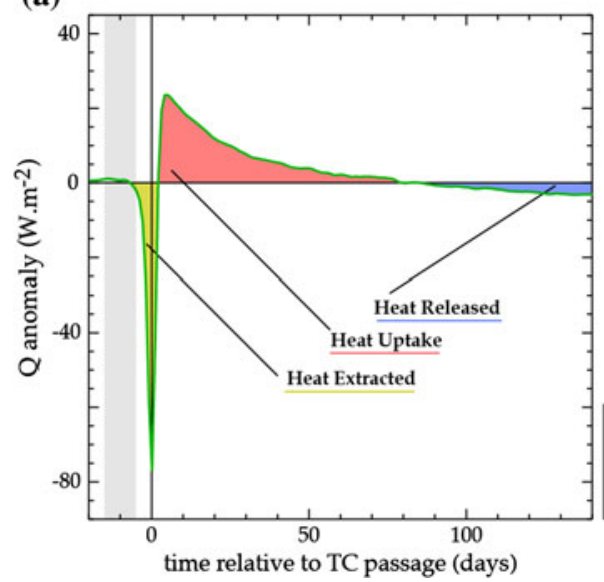

Fig. 12 Summarizing sketch: a Composite time series of TC-induced total surface flux anomalies within $600 \mathrm{~km}$ of TC-tracks (same curve as Fig. 4a) with annotations indicating our naming conventions for the different heat transfers induced by TCs. The ocean heat extracted by TCs (OHE) corresponds to the TC-induced enthalpy fluxes to the atmosphere during the cyclone passage. The ocean heat uptake $(\mathrm{OHU})$ is defined in the same way to other authors as the heat input from the atmosphere that is needed to dissipate the cold wake (i.e. the

OHE corresponds to the integral of the negative part (i.e. heat flux toward the atmosphere) of the surface heat flux difference between CYCL and FILT experiment at every timestep over the TCs duration and extent. OHE can hence be computed as $\mathrm{OHE}=\iint \min \left(Q^{\prime}, 0\right) d S d \tau$, where the double integral is done over all elementary surfaces $d S$ and elementary durations $d \tau$ within TCs footprint (within a $1,200 \mathrm{~km}$ radius of a TC track position). OHE represents (b)

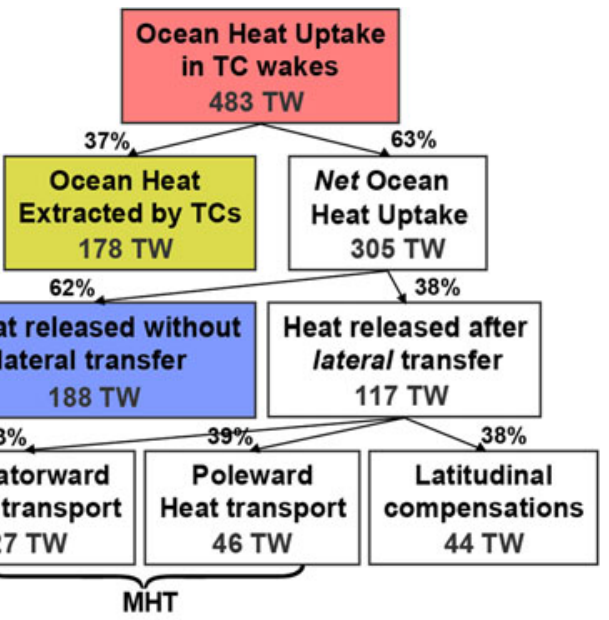

heat input to the ocean due in TCs' wake). Once the cold wake has been dissipated, subsurface anomalies re-emerge during the next winter and are associated with a delayed ocean heat release (OHR) to the atmosphere. Finally, a part of these subsurface anomalies is transported laterally before re-merging: this is the Ocean Heat Transport (OHT) while the remaining is released without lateral transfer. b Total heat uptake by the ocean $(\mathrm{OHU})$ in the wake of TCs and its partition into various components

the total amount of heat extracted from the ocean during the passage of TCs. The annual average global OHE over the 1983-2007 period estimated from our simulations is $178 \mathrm{TW}\left(1 \mathrm{TW}=10^{12} \mathrm{~W}\right)$.

Cold anomalies in the TCs' wake induce a positive heat flux into the ocean, i.e. a gain of heat for the ocean, the Ocean Heat Uptake (OHU). OHU is computed as the integral of the positive part of daily heat fluxes difference 
between CYCL and FILT experiments in all cyclonic basins over the 1983-2007 period $\mathrm{OHU}=\iiint \max$ $\left(Q^{\prime}, 0\right) d x d y d t$. Contrarily to the OHE calculation, the values are not cumulated only during TC passage (duration $d \tau$ and surface $d S$ ): any heat flux into the ocean (used to dissipate the TC cold wake) is accounted for. The longterm average of this heat uptake estimated from our simulations is $483 \mathrm{TW}$. This value can directly be compared to OHU estimates by Emanuel (2001): 1,400 TW, Sriver et al. (2008): 480 TW and Jansen et al. (2010): 580 TW. Our model estimate is in good agreement with these two most recent observation-based studies.

None of the previous studies accounted for the reduction of the OHU by the heat fluxes extracted during the TC passage (OHE). We define the net $\mathrm{OHU}$ as $\mathrm{OHU}$ minus OHE. The net OHU estimated from our simulations is $305 \mathrm{TW}$. This means that $\sim 2 / 5$ of the heat flux entering the ocean in the wake of TCs only compensates the heat extracted to the ocean during TC passage (Fig. 12). Only the remaining $\sim 3 / 5$ (the net $\mathrm{OHU}$ of $305 \mathrm{TW}$ ) actually induces a net warming of the ocean that may affect the ocean heat transport. Figure 13a shows the spatial distribution of the net OHU. A net total heat uptake of $185 \mathrm{TW}$ (resp. $120 \mathrm{TW}$ ) penetrates the ocean seasonal and main thermocline in the northern hemisphere (resp. southern hemisphere) in TC-prone regions.

The re-emergence of subsurface warm anomalies in the months following the cyclonic season induce a long-term SST warming, and hence a heat loss to the atmosphere (ocean heat release, or OHR, blue area on Fig. 12a indicates that some of the heat is released locally within the TC footprint). The total ocean heat loss is obtained as the integral of the negative part of the daily surface fluxes difference between CYCL and FILT experiments within TC basins over the 1983-2007 period. OHR is then computed as the difference between this total ocean heat loss and OHE to exclude from the calculation the heat lost directly under TCs and only account for the heat released well after TCs' passage (the spatial integral of OHR calculated in this way equals the net $\mathrm{OHU}$ ). The spatial pattern of the long-term averaged total OHR is shown on Fig. 13b. This heat is released back to the atmosphere in slightly different regions than where they were injected (compare Fig. 13a and b). The heat injected into the subsurface ocean during the TC season is indeed advected by the subtropical gyre and equatorial
Fig. 13 Average 1983-2007 a Net TC-induced ocean heat uptake $\left(>0, \mathrm{~W} / \mathrm{m}^{2}\right)$. The net heat uptake is the extra heat entering the ocean after the TCs passage (as the result of the cold wake; $\mathrm{OHU}$ ) minus the heat extracted from the ocean to the atmosphere during TCs passage (OHE, the enthalpy flux to the atmosphere that fuels the cyclone heat engine). b Net TCinduced ocean heat release $(<0$, $\mathrm{W} / \mathrm{m}^{2}$; OHR). The net heat release is the long-term TCinduced heat loss to the atmosphere that results from the re-emergence of subsurface warm mixing-induced anomalies after the end of the cyclonic season. c CYCL surface heat flux anomaly relative to FILT $\left(\mathrm{W} / \mathrm{m}^{2}\right)$; it is also the sum of the two fields shown in $\mathbf{a}$ and $\mathbf{b}$ and represents the total effect of TCs on surface heat fluxes, that has to be equilibrated by a change in ocean heat transport (OHT)

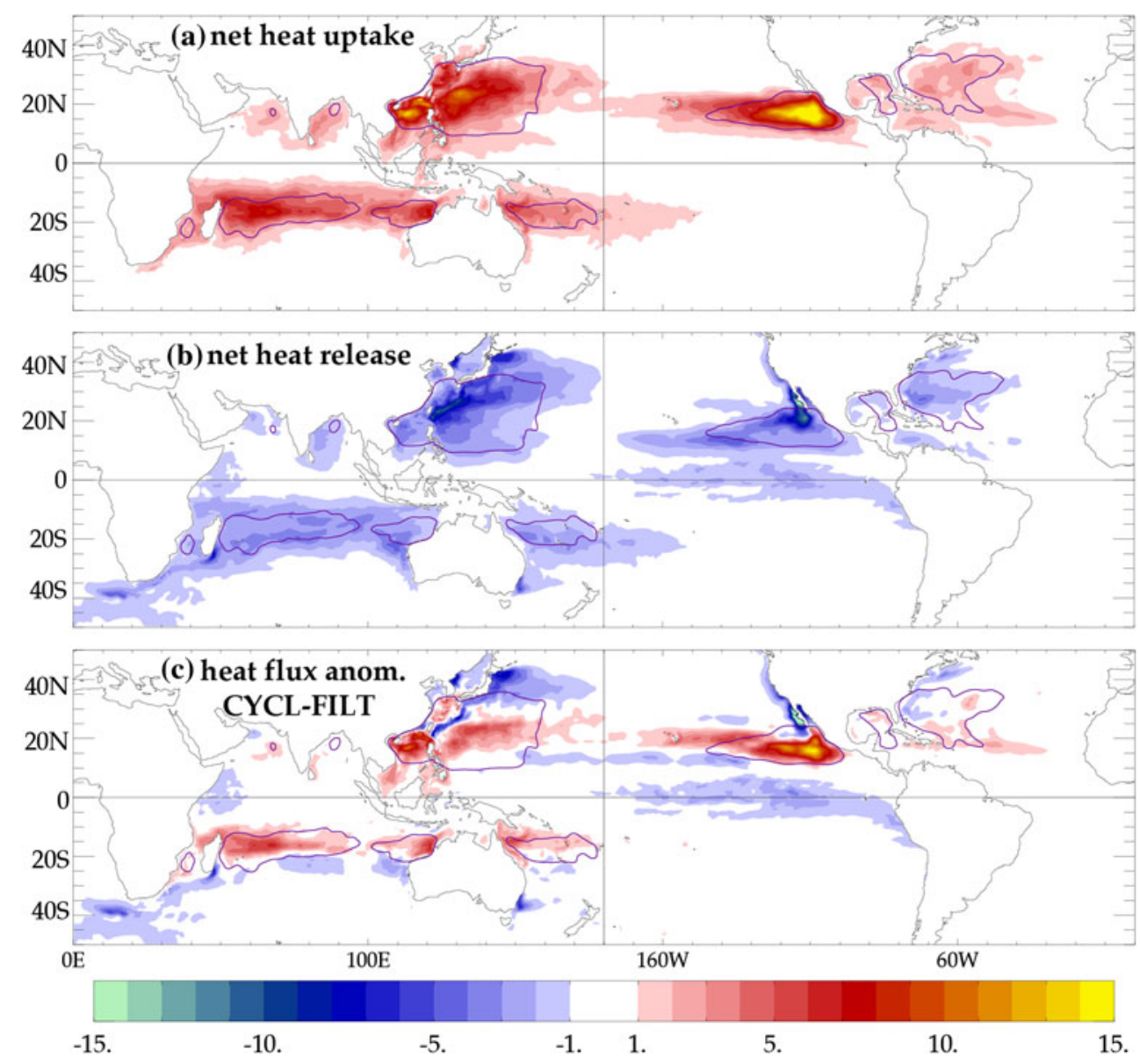


circulations, before being re-entrained in the mixed layer and released back to the atmosphere.

The average TC-induced heat flux anomaly between the CYCL and FILT simulations (equivalently obtained from the difference between the net heat uptake and heat released displayed in Fig. 13a, b) is shown in Fig. 13c. At equilibrium, this mean surface heat flux anomaly has to be balanced by an horizontal oceanic heat transport, carrying heat from regions of TC-induced fluxes into the ocean (positive values on Fig. 13c) to regions of TC-induced fluxes out of the ocean (negative values on Fig. 13c). The TC-induced ocean heat transport can hence be computed as OHT $=\iint \max \left(\bar{Q}^{\prime}, 0\right) d x d y$, where the overbar signifies temporal averaging, i.e. $\bar{Q}^{\prime}$ corresponds to Fig. $13 \mathrm{c}$. The resulting TC-induced OHT amounts to $117 \mathrm{TW}$. This is about $1 / 3$ of the net TC-induced OHU (i.e. about $2 / 3$ of the heat injected in the subsurface at a given point is later released to the atmosphere locally, because of the reemergence of subsurface warm anomalies; heat released without lateral transfer on Fig. 12).

A relevant quantity for earth's climate is the ocean Meridional Heat Transport (MHT), which can be obtained by averaging zonally the argument in the OHT integral. Zonally integrating this surface heat flux yields the amount of heat that the ocean needs to transport meridionally in order to compensate excesses or losses of surface heat flux in a given latitude band. At a given latitude, there is a partial compensation between positive and negative heat fluxes (Fig. 13c), so that only $2 / 3$ of the OHT results in a MHT. The total model MHT and anomalies induced by TCs are displayed on Fig. 14. The TC-induced MHT anomalies show a poleward heat export at $20^{\circ} \mathrm{S}$ and $25^{\circ} \mathrm{N}$ and an equatorward heat convergence between $10^{\circ} \mathrm{N}$ and $10^{\circ} \mathrm{S}$. This structure is very similar to the one displayed in previous studies (e.g. Jansen and Ferrari 2009; Scoccimarro et al. 2011). Overall, TCs result in an injection of $73 \mathrm{TW}$ in TC basins of which $27 \mathrm{TW}$ is released in the equatorial band and $46 \mathrm{TW}$ is released poleward $(18 \mathrm{TW}$ in the Northern hemisphere and $28 \mathrm{TW}$ in the Southern hemisphere). The overall TC-induced MHT change ends up being very small with respect to the total MHT of the model (Fig. 14): moreover, this MHT anomaly is largely driven by dynamical processes rather than vertical mixing (see "Appendix").

Figure $12 \mathrm{~b}$ summarizes how compensations finally reduce the $483 \mathrm{TW}$ OHU to a very modest $\sim 30-50 \mathrm{TW}$ change of equatorward/poleward heat transport by the meridional oceanic circulation. The largest compensations occur because of heat extraction by TC winds (178 TW) and release of TC-induced subsurface heat storage during winter (188 TW), with latitudinal compensation playing a lesser role $(44 \mathrm{TW})$.

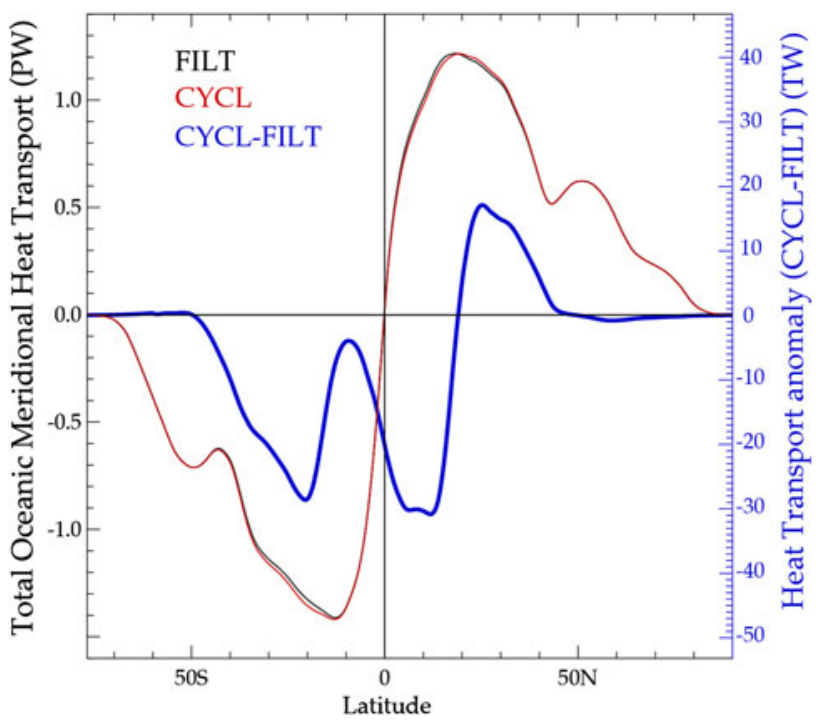

Fig. 14 Total oceanic Meridional Heat Transport in the model in the CYCL and FILT experiment and Meridional Heat Transport anomaly for TC forcing experiment (CYCL) relative to FILT (vertical scale for the anomaly indicated on the right)

\section{Conclusion}

\subsection{Summary}

Past studies investigating TCs impact on the ocean mean state and heat transport have focused on the effect of vigorous vertical mixing under TCs. Most of these studies crudely incorporated this effect by enhancing the vertical diffusivity coefficients in rather coarse ocean circulation models. Here, we adopt an alternative approach that also allows taking TC-induced surface fluxes and advection into account. We use an ocean general circulation model at $1 / 2^{\circ}$ resolution, forced from reconstructed wind perturbations associated with more than 3,000 observed TCs over 1978-2007. Vincent et al. (2012a) show that this forcing strategy allows simulating the TC-induced surface cooling reasonably well. Here, we focus on the climatological impact of the oceanic response to TC passages and perform sensitivity experiments that allow quantifying the respective contributions of TC-induced mixing, advective processes and surface heat fluxes.

All three processes significantly impact the ocean climatology, and have weak nonlinear interactions. TCs wind-driven heat fluxes dominate the large-scale surface cooling that affect the upper $30 \mathrm{~m}$ in all TC-basins. TCinduced mixing warms the sub-surface ocean down to $300 \mathrm{~m}$ depth by injecting warm surface waters into the thermocline. Our analysis also reveals that TC-induced dynamical processes have a global scale impact on the ocean thermal structure at depth. The wind pattern associated with individual TCs indeed results in a strong 
upwelling along their track compensated by downwelling on both sides of the eyewall. When averaged over the TC season, these signals induce a residual Ekman pumping with a well-defined spatial pattern: upwelling and a sealevel drop in the heart of TC-basins and downwelling and a sea level rise on the northern and southern flanks of these basins. Those sea-level signals expand westward to fill the entire basin as the result of planetary wave propagation (Fig. 3; Jansen et al. 2010).

The salient features of the resulting long-term mean oceanic response to these $\mathrm{TC}$-induced processes are:

(i) a cooling of the ocean surface in all TC-basins with maximum amplitude in the North Pacific (about $-0.4{ }^{\circ} \mathrm{C}$ ). All three processes contribute to this cooling, the TC-induced heat flux being dominant.

(ii) a subsurface warming over $10^{\circ}$ latitude bands centered around $25^{\circ} \mathrm{N}$ and $25^{\circ} \mathrm{S}$ and maximum in the Northwest Pacific $\left(\sim 0.4^{\circ} \mathrm{C}\right)$. The warming is largely due to TC-induced mixing at 30-200 m depth while TC-induced downwelling signals are responsible for the weak deeper warming signal.

(iii) a subsurface cooling over $10^{\circ}$ latitude bands centered around $15^{\circ} \mathrm{N}$ and $15^{\circ} \mathrm{S}$. TC-induced upwelling in the heart of the TC-basins is largely responsible for this cooling at depth (mixing induced warming and upwelling induced cooling almost cancel each other around $\sim 100 \mathrm{~m}$ depth).

(iv) a weak warming of the equatorial thermocline $\left(\sim 0.1^{\circ} \mathrm{C}\right)$ : this signal arise from near equator TC related downwelling signals and sub-surface equatorward advection of mixing induced warm anomalies.

The TCs impact on the ocean is strongly modulated at seasonal timescale. The summer TC-induced surface cooling does not persist during winter as it is damped within $\sim 2$ months. The TC-induced sub-surface warming mostly occurs in the seasonal thermocline. It is therefore largely re-entrained into the mixed layer and released back to the atmosphere during the following winter, as a result of seasonal mixed layer deepening. The TC-induced cooling in summer and warming in winter result in a $\sim 10 \%$ reduction of the SST seasonal cycle in TC-prone regions.

Because of the cold surface anomalies left in their wake, TCs induce an ocean heat uptake of 483 TW (OHU, as estimated by previous studies), but several compensations explain the resulting very modest $\sim 50$ TW Poleward Heat Transport (see the summarizing sketch of Fig. 12b). About $2 / 5$ of the 483 TW injected into the ocean in the wake of TCs simply compensate the heat extracted by the TC during its passage (178 TW), so that the heat injection rate to the ocean due to TCs is only 305 TW. As a consequence of the mixed layer depth seasonality, another $\sim 2 / 5$ of the OHU (188 TW) are re-entrained into the mixed layer and released back to the atmosphere in the same region during winter. Only 117 TW hence contribute to the ocean heat transport. When zonally averaged, only 73 TW remain for meridional heat transport, because of latitudinal compensations. $27 \mathrm{TW}$ is transported equatorward and $46 \mathrm{TW}$ is transported poleward. This TC-induced poleward heat transport is very weak compared to the total ocean heat transport in our simulation.

\subsection{Discussion}

Our results are consistent with most recent studies evaluating the TC-induced ocean heat uptake (OHU) from satellite observations. Sriver et al. (2008) and Jansen et al. (2010) estimated an OHU of 480 and $580 \mathrm{TW}$, respectively. Nevertheless, over the entire storm footprint, about half of the SST cooling is due to surface latent heat loss at the TC passage (Vincent et al. 2012a), which thus has to be deduced from the OHU to yield the net ocean heat uptake. In their study, Jansen et al. (2010) note that TCs occur primarily during summer and early fall, when the mixed layer is generally shallow. As the mixed layer deepens in the following winter, any warm anomaly deposited within the thermocline will be reabsorbed by the mixed layer and lost to the atmosphere. They suggest that only $150 \mathrm{TW}$ $( \pm 100 \%)$ are injected deep enough (i.e. into the permanent thermocline) to contribute to OHT, in agreement the 117 TW found in the present study.

Most previous studies have parameterized TCs effect by including an additional vertical mixing up to some fixed depth. In the current paper, the model explicitly computes this additional mixing under each individual cyclone. In both cases, results heavily depend upon the maximum depth to which TCs mixing penetrates. If warm sub-surface anomalies are located within the seasonal thermocline, these anomalies cannot efficiently contribute to the ocean heat transport as they are released back to the atmosphere during the following winter. Only temperature anomalies residing in the permanent thermocline can really alter the OHT. There is a clear lack of observational data and modeling studies to allow for an accurate quantification of the TC-induced mixing depths. We however argue that our model results are realistic as the simulated TCs cold wake intensity compares well with observations (Vincent et al. 2012a). Given that this cold wake mainly results from penetrative mixing, a correct mean thermal structure and correct surface cooling amplitude in the model implies that cold water has been entrained from the right depth and that the model mixing depth under TCs is reasonable. 
Shallow sub-surface processes may however not be the only way through which TCs impact the ocean. Nearinertial waves generated in the wake of TCs propagate in the thermocline and below and induce deep mixing (e.g. Le Vaillant et al. 2012). Our simulation does not properly resolve such small-scale phenomena. In addition, even if the order of magnitude of TC-induced upwelling is correct in our simulation, increased resolution may yield more realistic TC-induced upwelling/downwelling. Higher resolution simulations could also be useful in investigating the role of mixed layer instabilities in restratifying the mixed layer and damping of the TCs' cold wake (Boccaletti et al. 2007). Additional experiments at higher resolution are therefore required to confirm the present results and explore further impacts that TCs may have on the ocean and climate.

The present study suggests that TCs do not significantly impact the poleward ocean heat transport. It however suggests that TCs strongly impact the amplitude of the SST seasonal cycle in convective TC-prone regions. The use of a forced model does not allow us to assess the importance of this seasonal TC-related heat flux on the coupled climate system but one can speculate that this seasonal cycle buffering effect may affect the climate system in coupled mode. A methodology to account for this impact of TCs in a coupled system is currently being developed to further investigate this impact.

Acknowledgments Experiments were conducted at the Institut $d u$ Développement et des Ressources en Informatique Scientifique (IDRIS) Paris, France. We thank the Nucleus for European Modelling of the Ocean (NEMO) Team for its technical support. The analysis was supported by the project Les enveloppes fluides et l'environnement (LEFE) CYCLOCEAN AO2010-538863 and European MyOcean project EU FP7. We thank Malte Jansen as well as an anonymous reviewer for their helpful comments.

\section{Appendix: Contribution of each process to the MHT anomaly}

The linear approximation to separate the respective contribution of the three main TC-induced processes (mixing, dynamical response and surface heat flux) also appears reasonable for heat transport anomalies. The sum of the three processes only underestimate CYCL MHT anomalies by $\sim 10 \%$. The three processes play a significant role in driving TC-induced MHT changes (Fig. 15). The effect of TC-induced mixing is in agreement with previous studies (Emanuel 2001; Sriver et al. 2008; Korty et al. 2008; Jansen and Ferrari 2009). Vigorous vertical mixing below TCs acts to inject heat downward. This heat stored in subsurface is then exported both poleward and equatorward by the oceanic circulation (Jansen and Ferrari 2009).

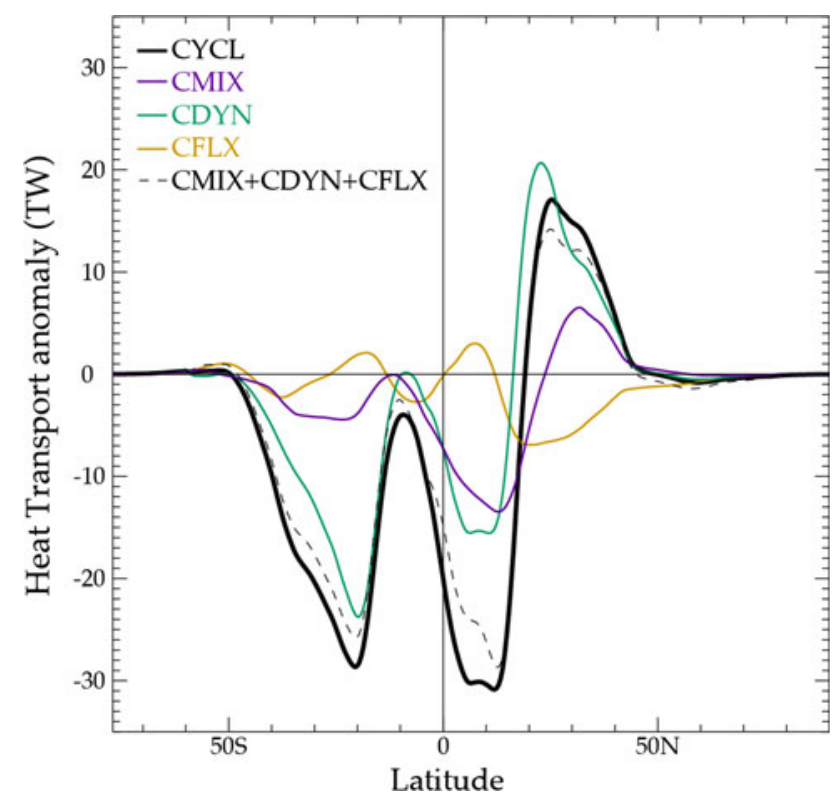

Fig. 15 Meridional Heat Transport anomalies relative to FILT, for TC forcing experiment (CYCL: thick black curve is the same as the blue curve in Fig. 13), TC forcing acting on vertical mixing only (CMIX), on advection only (CDYN) and on surface heat fluxes only (CFLX)

Our analysis also reveals a poorly discussed contribution of TC-induced dynamical response (Scoccimarro et al. 2011). The mean upwelling generated by TCs induces a surface cooling, even in the absence of TCinduced mixing (Fig. 7c). This cooling is compensated by a net surface heat flux into the ocean, and hence a heat transport change. On poleward and equatorward flanks of TC-basins, the opposite effect occurs: the residual TCinduced downwelling induces a net heat loss. This results in a MHT change that has a similar shape but a much larger magnitude than the one due to TC-induced vertical mixing (Fig. 15). This contribution of TC-induced dynamical processes to the MHT is in agreement with previous results by Scoccimarro et al. (2011) who argued that TCs slightly modify the mean ocean circulation with impacts on the MHT.

The contribution of surface heat fluxes acts in opposition to the two previous effects. At the TC passage, surface heat fluxes cool the mixed layer. The subsequent fast warming restores the SST back to its background value, but this warming occurs over a shallower mixed layer, leaving behind a cold anomaly just below it. This cold anomaly is advected poleward and equatorward by the oceanic circulation before being re-entrained in the mixed layer the following winter. The related net surface fluxes are then negative in the re-emergence regions. Their effect on MHT therefore opposes the one related to mixing and advection. 


\section{References}

Axell LB (2002) Wind-driven internal waves and langmuir circulations in a numerical ocean model of the southern baltic sea. J Geophys Res 107. doi:10.1029/2001JC000922

Biastoch A, Böning CW, Schwarzkopf FU, Lutjeharms JRE (2009) Increase in Agulhas leakage due to poleward shift of Southern Hemisphere westerlies. Nature 462. doi:10.1038/nature08519

Blanke B, Delecluse P (1993) Variability of the tropical Atlantic Ocean simulated by a general circulation model with two different mixed-layer physics. J Phys Oceanogr 23(7): $1363-1388$

Boccaletti G, Ferrari R, Fox-Kemper B (2007) Mixed layer instabilities and restratification. J Phys Oceanogr 37:2228-2250

Burchard H (2002) Energy-conserving discretisation of turbulent shear and buoyancy production. Ocean Model 4:347-361. doi: 10.1016/S1463-5003(02)00009-4

Emanuel KA (1986) An air-sea interaction theory for tropical cyclones. Part 1: Steady-state maintenance. J Atmos Sci 43(6): 585-604

Emanuel KA (2001) Contribution of tropical cyclones to meridional heat transport by the oceans. J Geophys Res 106(14):771-781

Emanuel KA (2005) Increasing destructiveness of tropical cyclones over the past 30 years. Nature 436:686-688. doi:10.1038/ nature 03906

Enfield DB, Allen JS (1983) The generation and propagation of sea level variability along the Pacific coast of Mexico. J Phys Oceanogr 13(6): 1012-1033

Fasullo JT, Trenberth KE (2008) The annual cycle of the energy budget. Part II: Meridional structures and poleward transports. J Clim 21:2314-2326

Gill AE (1982) Atmosphere-Ocean dynamics, vol 30. Academic Press, New York

Griffies S et al (2009) Coordinated ocean-ice reference experiments (COREs). Ocean Model 26:1-46. doi:10.1016/j.ocemod.2008. 08.007

Halliwell GR, Shay LK, Brewster JK, Teague WJ (2011) Evaluation and sensitivity analysis of an ocean model response to Hurricane Ivan. Mon Wea Rev 139:921-945

Hart RE (2011) An inverse relationship between aggregate northern hemisphere tropical cyclone activity and subsequent winter climate. Geophys Res Lett 38:L01705. doi:10.1029/2010GL045612

Jansen MF, Ferrari R (2009) Impact of the latitudinal distribution of tropical cyclones on ocean heat transport. Geophys Res Lett 36:L06604

Jansen MF, Ferrari R, Mooring TA (2010) Seasonal versus permanent thermocline warming by tropical cyclones. Geophys Res Lett 37:L03602. doi:10.1029/2009GL041808

Jullien S, Menkes CE, Marchesiello P, Jourdain NC, Lengaigne M, Koch-Larrouy A, Lefèvre J, Vincent EM, Faure V (2012) Impact of tropical cyclones on the heat budget of the South Pacific Ocean. J Phys Oceanogr (in press)

Keerthi MG, Lengaigne M, Vialard J, de Boyer Montégut C, Muraleedharan PM (2012) Interannual variability of the Tropical Indian Ocean mixed layer depth. Clim Dyn. doi:10.1007/ s00382-012-1295-2

Knapp KR, Kruk MC, Levinson DH, Diamond HJ, Neumann CJ (2010) The international best track archive for climate stewardship (IBTrACS): unifying tropical cyclone data. Bull Am Meteorol Soc 10:363-376. doi:10.1175/2009BAMS2755.1

Korty RL, Emanuel KA, Scott JR (2008) Tropical cyclone-induced upper-ocean mixing and climate: application to equable climates. J Clim 21:638-654

Large W, Yeager S (2009) The global climatology of an interannually varying air-sea flux data set. Clim Dyn 33:341-364
Le Vaillant X, Cuypers Y, Bouruet-Aubertot P, Vialard J, McPhaden MJ (2012) Tropical storm-induced near-inertial internal waves during the Cirene experiment: energy fluxes and impact on vertical mixing. J Geophys Res (in revision)

Lengaigne M, Haussman U, Madec G, Menkes C, Vialard J (2012) Mechanisms controlling Warm Water Volume interannual variations in the Equatorial Pacific: diabatic versus adiabatic processes. Clim Dyn 38(5-6):1031-1046. doi:10.1007/s00382-011-1051-z

Locarnini RA et al (2010) World ocean atlas 2009, vol 1: Temperature. In: Levitus S (ed) NOAA atlas NESDIS 68. US Government Printing Office, Washington

Madec G (2008) NEMO ocean engine, Note du Pôle de modélisation, Institut Pierre-Simon Laplace (IPSL), France, ISSN no 27:12881619

Manucharyan GE, Brierley CM, Fedorov AV (2011) Climate impacts of intermittent upper ocean mixing induced by tropical cyclones. J Geophys Res 116:C11038. doi:10.1029/2011JC007295

Marsaleix P et al (2008) Energy conservation issues in sigmacoordinate free-surface ocean models. Ocean Model 20:61-89. doi:10.1016/j.ocemod.2007.07.005

Mellor G, Blumberg A (2004) Wave breaking and ocean surface layer thermal response. J Phys Oceanogr 34(3):693-698. doi:10.1175/ 2517.1

Neetu M, Lengaigne M, Vincent EM, Vialard J, Madec G, Samson G, Kumar R, Durand F (2012) Influence of upper-ocean stratification on tropical cyclones-induced surface cooling in the Bay of Bengal. J Geophys Res (in revision)

Nidheesh AG, Lengaigne M, Vialard J, Unnikrishnan AS, Dayan H (2012) Decadal and long-term sea level variability in the tropical Indo-Pacific Ocean. Clim Dyn. doi:10.1007/s00382-012-1463-4

Park JJ, Kwon YO, Price JF (2011) Argo array observation of ocean heat content changes induced by tropical cyclones in the North Pacific. J Geophys Res 116:C12025. doi:10.1029/2011JC007165

Penduff $T$ et al (2010) Impact of global ocean model resolution on sea-level variability with emphasis on interannual time scales. Ocean Sci 6:269-284

Price JF, Morzel J, Niiler PP (2008) Warming of SST in the cool wake of a moving hurricane. J Geophys Res 113:C07010. doi: 10.1029/2007JC004393

Scoccimarro E, Gualdi S, Bellucci A, Sanna A, Fogli PG, Manzini E, Vichi M, Oddo P, Navarra A (2011) Effects of tropical cyclones on ocean heat transport in a high resolution coupled general circulation model. J Clim 24(16):4368-4384. doi:10.1175/2011JCLI4104.1

Sriver RL, Huber M, Nusbaumer J (2008) Investigating tropical cyclone-climate feedbacks using the TRMM Microwave Imager and the Quick Scatterometer. Geochem Geophys Geosyst 9:Q09V11. doi:10.1029/2007GC001842

Sriver RL, Goes M, Mann ME, Keller K (2010) Climate response to tropical cyclone-induced ocean mixing in an Earth system model of intermediate complexity. J Geophys Res 115. doi:10.1029/ 2010JC006106

Trenberth KE, Fasullo J (2007) Water and energy budgets of hurricanes and implications for climate change. J Geophys Res 112:D23107. doi:10.1029/2006JD008304

Vincent EM, Lengaigne M, Madec G, Vialard J, Samson G, Jourdain NC, Menkes CE, Jullien S (2012a) Processes setting the characteristics of Sea Surface Cooling induced by Tropical Cyclones. J Geophys Res 117:C02020. doi:10.1029/2011JC007396

Vincent EM, Vialard J, Lengaigne M, Madec G, Masson S, Jourdain NC (2012b) Assessing the oceanic control on the amplitude of sea surface cooling induced by tropical cyclones. J Geophys Res 117:C05023. doi:10.1029/2011JC007705

Willoughby HE, Darling RWR, Rahn ME (2006) Parametric representation of the primary hurricane vortex. Part II: A new family of sectionally continuous profiles. Mon Wea Rev 134:1102-1120 